\title{
Çapakçur Vadisi (Bingöl) Buğdaygil (Poaceae) Florası
}

\section{Lütfi-BEHÇET ${ }^{1}, Y^{2}$ akup-YAPAR ${ }^{2}$ \\ 1,2Department of Biology, Faculty of Science and Art, Bingöl University, 12000, Bingöl, Turkey ${ }^{1}$ https://orcid.org/0000-0001-8334-7816, ${ }^{2}$ https://orcid.org/0000-0002-5298-0085 \\ $\bowtie$ : yyapar25@gmail.com}

\begin{abstract}
ÖZET
Bingöl, bitki çeşitliliği konusunda çalışmaların oldukça yetersiz olduğu bir ildir. Bu araştırmada, Bingöl Çapakçur Vadisi Buğdaygil (Poaceae) familyası florası verilmiştir. Tespit edilen taksonların yayılışları ile Türkiye ve komşu ülke floralarında verilen betimlemelere göre 26 taksonda varyasyon belirlenmiştir. $\mathrm{Bu}$ taksonlardan özellikle Alopecurus arundinaceus türünde stolon yapısının bulunması, hem Türkiye hem komşu ülke floralarında verilen betimlemelerden farklılık göstermektedir. Yapılan çalışmalar ve teşhisler sonucunda, araştırma sahasından 59 cinse ait toplam 151 takson (104 tür, 39 alttür ve 8 varyete) tespit edilmiştir. 2015 yılında Bingöl'den toplanıp; bilim dünyasına kazandırılmış olan Pseudophleum anatolicum ve 2019 yılında tanımlanan Pilgerochloa major türleri sadece Bingöl'den bilinen dar yayılışlı endemikler olup; araştırma alanında da yetiştiği belirlenmiştir. Çalışmada belirlenen taksonların 10 adedi endemik (\%6.62) ve 26 adedi B8 karesi için yeni kayıttır. Çapakçur Vadisi Poaceae florasını oluşturan taksonların 29 adedi (\%19.21) İran-Turan, 20 adedi (\%13.24) Avrupa-Sibirya ve 9 adedi (\%5.96) Akdeniz fitocoğrafik bölge elementidir. Geriye kalan taksonlar ya çok bölgeli veya fitocoğrafik bölgesi bilinmeyenlerdir.
\end{abstract}

\section{The Grasses (Poaceae) Flora of Çapakçur Valley (Bingöl)}

\begin{abstract}
Bingöl is a province where studies on plant diversity are quite insufficient. In this study, Bingöl Çapakçur Valley Grasses (Poaceae) family flora was presented. Variations were determined in 26 taxa of this area based on the distribution in identified taxon descriptions given in Turkey and in neighboring countries flora. The presence of this kind of stolon structure, in particular Alopecurus arundinaceus taxa differ from descriptions given in both Turkey and neighboring countries flora. As a result of the sample collection studies and identifications, a total of 151 taxa (104 species, 39 subspecies and 8 varieties) belonging to 59 genera were determined from the research area. Collected from Bingöl in 2015; Pseudophleum anatolicum and Pilgerochloa major species, which were introduced to the world of science, were narrow spread endemics known only from Bingöl and it were determined in the study field. Overall, 10 of the taxa determined in the study were endemic (6.62\%) and 26 were new records for the B8 square. Çapakçur Valley Poaceae Flora constituted of 29 of the taxa $(19.21 \%)$ of Iran-Turan, $20(13.24 \%)$ of European-Siberian and 9 $(5.96 \%)$ of Mediterranean phytogeographical region elements. The remaining taxa were either multi-regional or unknown of phytogeographical region.
\end{abstract}

Araştırma Makalesi

\section{Makale Tarihçesi}

Geliş Tarihi : 22.08.2020

Kabul Tarihi : 02.10.2020

\author{
Anahtar Kelimeler \\ Bingöl \\ Poaceae (Gramineae) \\ buğdaygil \\ biyoçeşitlilik
}

\section{Research Article}

$\begin{array}{ll}\text { Article History } & \\ \text { Received } & : 22.08 .2020 \\ \text { Accepted } & : 02.10 .2020\end{array}$

Keywords
Bingöl
Poaceae (Gramineae),
Grasses
biodiversity

Atıf İçin: Behçet L, Yapar Y 2021. Çapakçur Vadisi (Bingöl) Buğdaygil (Poaceae) Florası. KSÜ Tarım ve Doğa Derg 24 (3): 539-553. https://doi.org/10.18016/ksutarimdoga.vi.784144.

To Cite: $\quad$ Behçet L, Yapar Y 2021. The Grasses (Poaceae) Flora of Çapakçur Valley (Bingöl). KSU J. Agric Nat 24 (3): 539553. https://doi.org/10.18016/ksutarimdoga.vi.784144.

GİRIŞ

Doğu Anadolu Bölgesinin Yukarı Fırat bölümünde yer alan Bingöl; doğusunda Muş, kuzeyinde Erzurum ve Erzincan, batısında Tunceli ve Elazı̆̆g, güneyinde ise 
Diyarbakır illeri ile çevrilidir. Doğu Anadolu bölgesi ile Güneydoğu Anadolu bölgesi arasındaki bir geçiş kuşağında yer alan Bingöl; sahip olduğu ekolojisi ile çevresindeki illere göre farklı özelliklere sahiptir. Örneğin; güneyindeki Diyarbakır'da yıllık yağış miktarı 486.7 mm, kuzey komşusu Erzurum'da 432 mm ve batı komşusu Elazığ'da 412 mm iken; Bingöl'de yıllık yağış miktarı 946.5 mm'dir. Buna göre Bingöl, çevresindeki illerin aldığı yağışın 2 mislinden daha fazla yağış almaktadır. Karadeniz'e olan mesafesi (kuşuçuşu) yaklaşık $220 \mathrm{~km}$ olan Bingöl'e düşen yıllık yağış miktarı, Karadeniz bölgesindeki bazı illerden de fazladır (Çizelge 1). Diğer taraftan güneyden gelen sıcak iklim etkisi de Bingöl ekolojisinin oluşumunda önemli etkiye sahiptir.

Araştırma alanı Çapakçur Vadisi; Bingöl şehir merkezinden batıya doğru Palu (Elazığ) ilçe sınırına kadar uzanan, yaklaşı $50 \mathrm{~km}$ uzunluk ve $30 \mathrm{~km}$ genişlikte olan, deniz seviyesine göre 2000 metreyi aşan yükseltilere sahip, son derece engebeli bir vadidir (Şekil 1). Orman örtüsünün aşırı tahrip edildiği Yelesen ve Balpınarı (Matan) köylerinde, eğim ve erozyonun da etkisiyle ağaçsız çıplak kayalıkların hakim olduğu fizyonomi oluşmuştur (Şekil 2).

Bitki çeşitliliği yeterince araştırılmamış olan Bingöl'de 2015 yılından günümüze kadar yapılan yoğun çalışmalar sonucu 2'si Poaceae familyasından olmak üzere toplam 6 bitki türü bilim dünyasına "yeni tür" olarak tanitılmıştır (Doğan ve ark., 2015; Behçet ve İlçim 2015; Duran ve ark., 2015; İlçim ve Behçet, 2016; Behçet ve ark., 2017; Doğan ve Behçet, 2019). Tanımlanan bu 6 lokal endemik türden 5'inin Çapakçur Vadisinde yetiştiği tespit edilmiştir.

Sahip olduğu toplam takson sayısı bakımından dünyanın beşinci familyası olan Poaceae; Türkiye florasının dördüncü büyük familyasıdır (Ersoy ve ark., 2019). Insan ve hayvan beslenmesinde temel besin kaynağı olan bir çok cins (Hordeum L., Oryza L.,

Çizelge 1. Bingöl ve Bingöl'e komşu iller (Elazığ, Diyarbakır, Erzurum) ile Trabzon iline ait toplam yağış (P), en sicak ayın maksimum sıcaklık ortalamaları $(\mathrm{M})$ ve en soğuk ayın minimum sicaklık ortalamaları (m)

Table 1. Belonging to Bingöl and neighboring provinces (Elazig, Diyarbakır, Erzurum) and Trabzon province, averages of total precipitation $(P)$, maximum temperature averages of the hottest month $(M)$ and minimum temperature averages of the coldest month $(\mathrm{m})$

\begin{tabular}{|l|c|c|c|}
\hline $\begin{array}{l}\text { İSTASYON } \\
\text { (STATION) }\end{array}$ & $\begin{array}{l}\text { Toplam yıllık yağ } \\
\text { miktarı } \\
\text { precipitation }(P) \text { mm) }\end{array}$ & $\begin{array}{l}\text { En sicak ayı maksimum } \\
\text { sicaklı ortalaması (Maximum } \\
\text { temperature average of the } \\
\text { hottest month }(M)^{\circ} \mathrm{C} \text { ) }\end{array}$ & $\begin{array}{l}\text { En soğuk ayın minimum } \\
\text { sicaklı ortalaması, (Minimum } \\
\text { temperature averages of the } \\
\text { coldest month }(\mathrm{m})^{\circ} \mathrm{C} \text { ) }\end{array}$ \\
\hline BİNGÖL & 946.5 & 34.6 & -6.1 \\
\hline ELAZIĞ & 412 & 34.3 & -4 \\
\hline DiYARBAKIR & 486.7 & 38.5 & -2.5 \\
\hline ERZURUM & 432 & 27.2 & -14 \\
\hline TRABZON & 820.6 & 26.8 & 4.3 \\
\hline
\end{tabular}

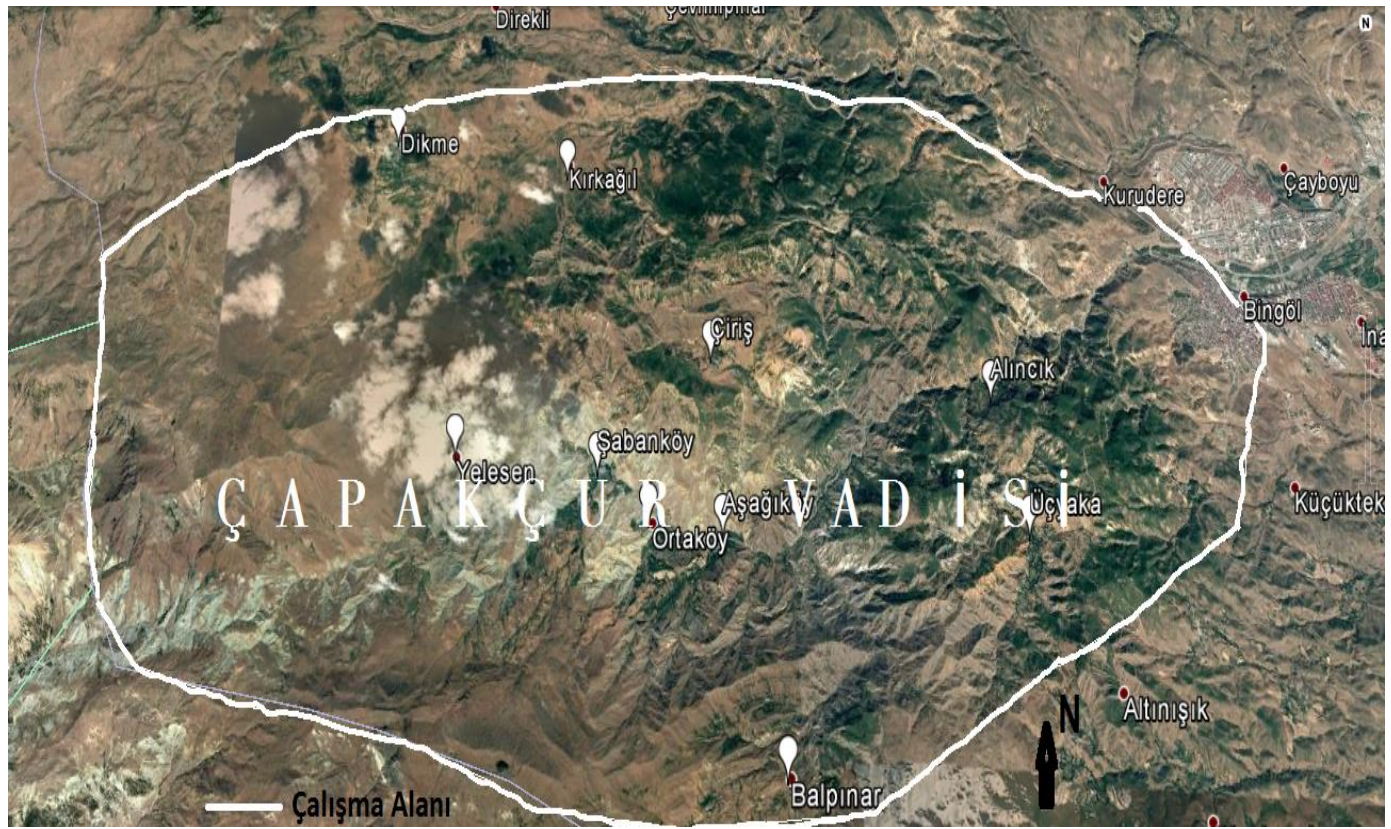

Şekil 1. Çalışma alanının haritası

Figure 1. Map of the study area 


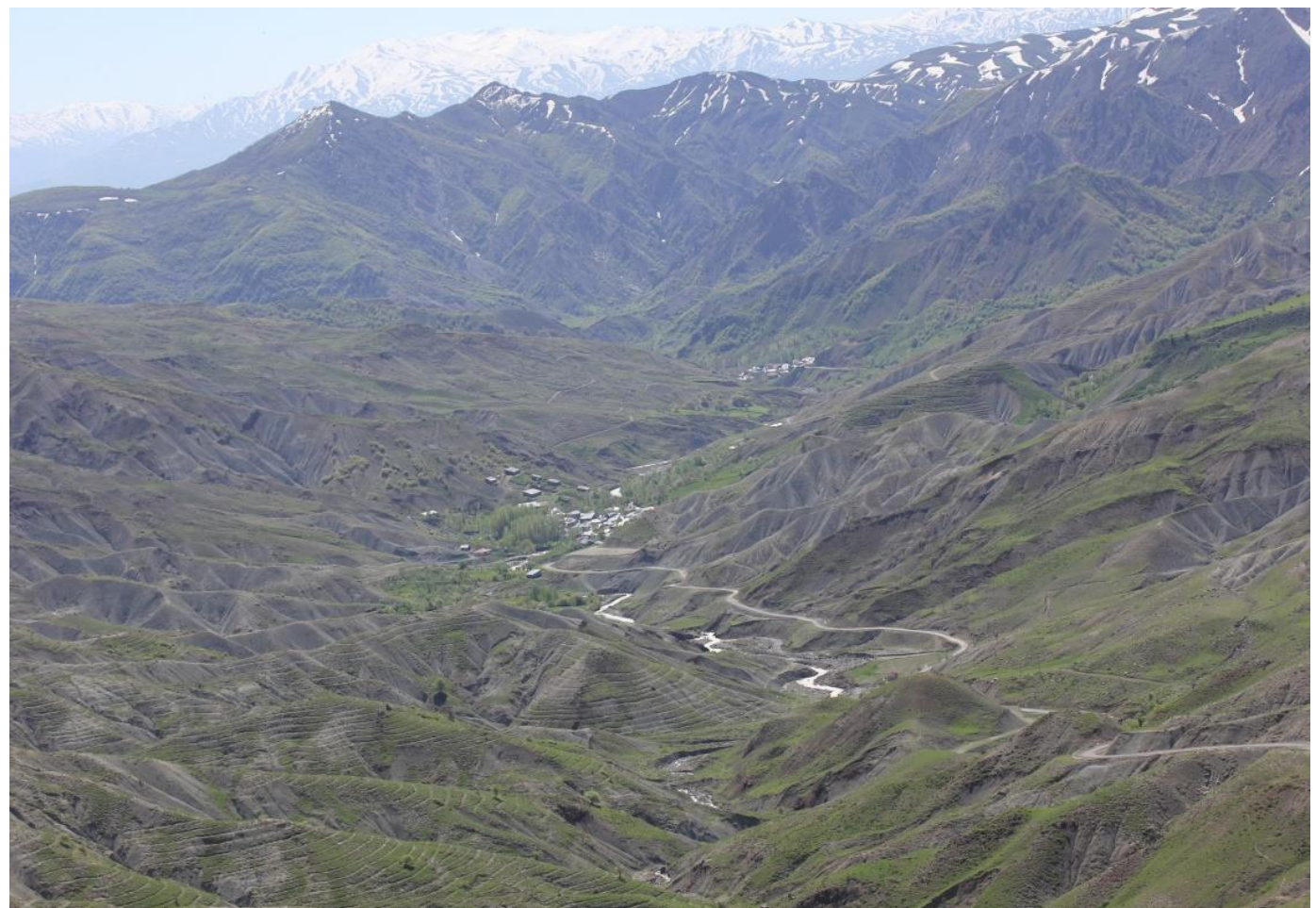

Şekil 2. Çapakçur Vadisinde ormanın tahrip edildiği ve erozyona maruz kalan kesimden bir görünüm Figure 2. A view from the section where the forest was destroyed and exposed to erosion in the Capakçur valley.

Panicum L., Saccharum L., Secale L., Triticum L., Zea L. ) içeren familya, sadece ekonomik değil, aynı zamanda ekolojik açıdan da büyük öneme sahiptir. Son yıllarda tanımlanan yeni taksonlar göstermektedir ki, Türkiye Poaceae florası henüz tam olarak belirlenememiştir. Bu çalışmada, Türkiye Poaceae florasına taksonomik ve korolojik bakımdan katkı sağlamak amaç edinilmiştir.

\section{MATERYAL ve METOT}

Çalışma materyalini 2011-2020 yılları arasında Çapakçur Vadisinde (Bingöl) yapılmış arazi çalışmaları esnasında toplanan Poaceae örnekleri oluşturmaktadir. Herbaryum materyali haline getirilen örneklerin teşhisinde büyük ölçüde Flora of Turkey and the East Aegean Islands, Flora of the U.S.S.R., Flora of Iraq, Flora Iranica ve Flora Europaea'nın ilgili ciltlerinden de faydalanıldı (Rozhevits ve Shishkin, 1963; Bor, 1968; 1970; Tutin, 1977; Davis ve ark., 1985). Ayrica bazı taksonların teşhisinde Cabi ve ark., (2011), Doğan ve ark., (2015) ve Doğan ve Behçet (2019)'in çalışmalarından da faydalanılmıştır. Çalışmada takson listesi alfabetik olarak verilmiştir. Listede; türün Latince adı, otörü, Türkçe adı, toplanma adresi (köy, mahalle, mevkii), habitat, yükseklik, toplama tarihi, toplayıcı adı ve numarası verilmiştir. Tekrardan kaçınmak için, adreslerin baş kısmına "Bingöl, Çapakçur Vadisi" yazılmamıştır. Endemik ise "end." kısaltması, belli ise fitocoğrafik bölgesi ve B8 karesi için yeni olan takson isimleri başına “*” işareti koyulmuş̧ur. B8 karesi için yeni taksonların belirlenmesinde ilgili yayınlardan faydalanılmıştır (Behçet ve ark., 2014; Sinan ve Behçet, 2014; Yıldırımlı, 2017; Yapar ve Behçet, 2018). Bazı taksonların varyasyon gösteren yapıları ile ilgili açıklamalar taksonun altında belirtilmiştir (varyasyonlar verilirken yazılan Türkiye florası ifadesinden kasit Flora of Turkey and the East Aegean Islands eserin ilgili cildidir). Verilen taksonlara ait örnekler; Bingöl Üniversitesi, Fen-Edebiyat Fakültesi, Biyoloji Bölümü Herbaryumunda (BIN) saklanmaktadir. Bitkilerin endemizim durumları, yazar isimleri ve Türkçe isimleri Türkiye Bitkileri Listesi (Cabi ve Doğan, 2012) adlı eserden kontrol edilmiştir. Endemik bitkilerin tehlike kategorileri Ekim ve ark., 2000; Doğan ve ark., 2015; Doğan ve Behçet 2019 çalışmalarından faydalanılarak verilmiştir.

\section{BULGULAR}

\section{Aegilops biuncialis Vis. / ikikılçık}

Aşağı ı̈öy-Ortaköy arası, orman açıkları, $1680 \mathrm{~m}$, 16.06.2020, Behçet \& Yapar 18511.

\section{A. columnaris Zhukovsky / kıl buğday}

Aşağılköy'e $1 \mathrm{~km}$ kala, yolun solundaki vadi, bozkır, 1600 m, 28.07.2019, Behçet \& Yapar 17747, İranTuran.

\section{A. cylindrica Host / kirpikli ot}

Bingöl Üniv. Fen-Edebiyat Fakültesi önü, nemli alan, 1100-1150 m, Behçet 7714, İran-Turan.

4. $\quad A$. neglecta Req. ex Bertol. / tüylü buğday Üçyaka-Balpınarı köyleri arası, ca. 2. km, orman açıkları, 1650-1700 m, 23.06.2019, Behçet \& Yapar 16896, Akdeniz. 
5. A. triuncialis L. subsp. triuncialis / üçkılçık Alıncak-Aşağıköy arası, mezarlık civarı, yol kenarları, 1413 m, 17.06.2020, Behçet \& Yapar 18596.

6. A. umbellata Zhuk. / hanım buğdayı

Bingöl merkez, mezarlık batısı, taş ocağı yol ayrımı, orman açıkları, 1200-1300 m, 22.05.2018, Behçet \& Yapar 15018, Iran-Turan.

7. Agrostis canina L. / kadife tavusotu
Yelesen köyü güneyi, Metan Dağı, bozkır yamaçlar, 1900 m, 10.08.2019, Behçet 10358; Yelesen köyü kuzeybatısı, yayla yolu 4 . km, kayalık yamaçlar, 2275 m, 02.07.2018. Behçet \& Yapar 15534, Avrupa-Sibirya. Panicula uzunluğu 22.5 cm'ye varıyor (Türkiye florasında 3.5-11 cm), Panikula Buranslar 4.5 cm'ye varıyor (Türkiye florasında c. $3 \mathrm{~cm}$ ) (Şekil 3).

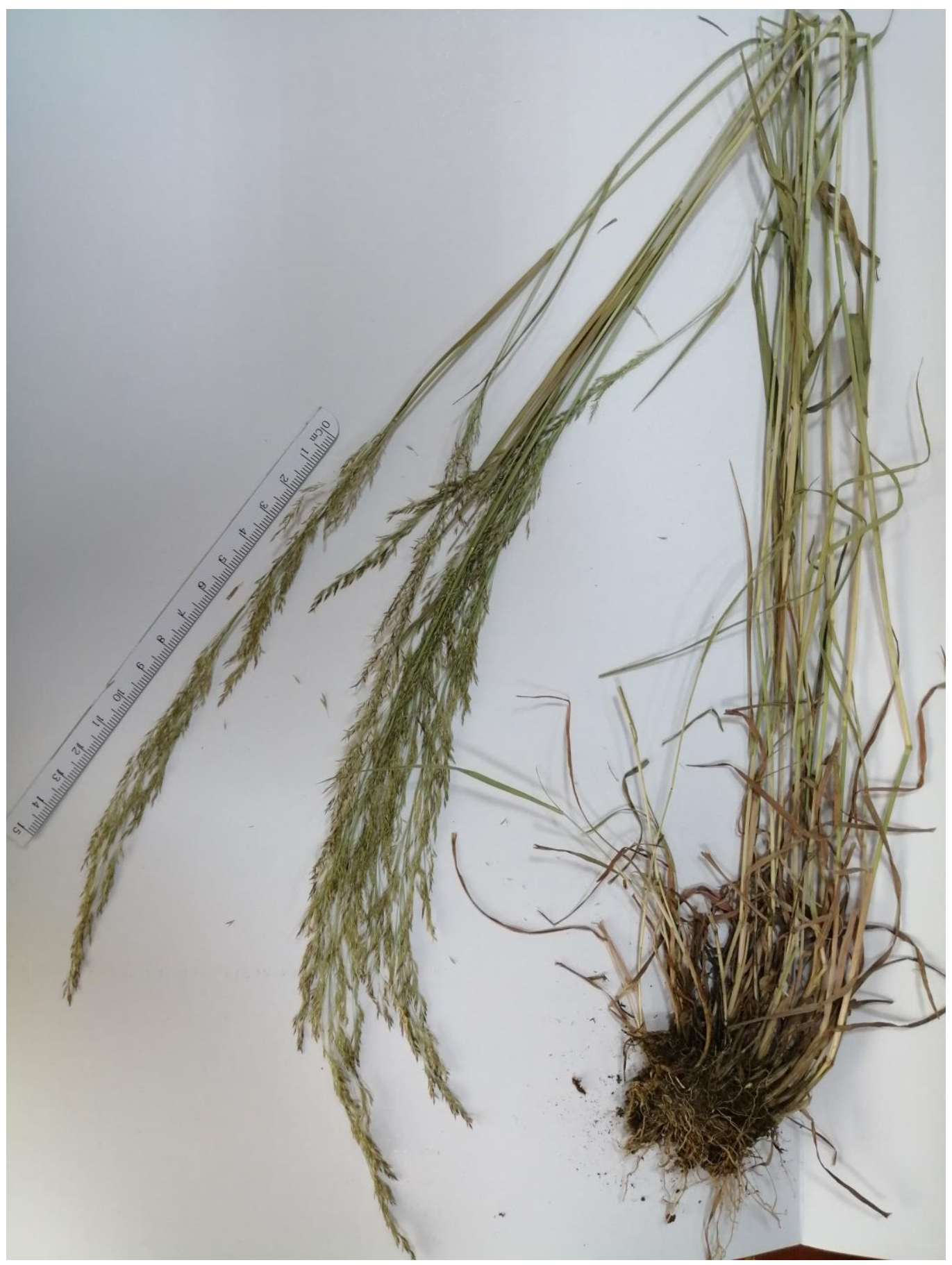

Şekil 3. Agrostis canina genel görünüşü

Figure 3. Agrostis canina general view

8. A. gigantea Roth / koca tavusotu

Alıncak-Aşağıköy arası, 10. km, dere kenarı, $1410 \mathrm{~m}$, 08.07.2018, Behçet \& Yapar 15779, Avrupa-Sibirya.
Yaprak aya uzunluğu 40 cm'ye varıyor (Türkiye florasında $3.5-20 \mathrm{~cm}$ ), infloresans boyu $32 \mathrm{~cm}$ (Türkiye florasinda 28 cm'ye variyor). 
9. $\quad *$ A. olympica (Boiss.) Bor / ulu tavusotu

Yelesen köyü yayla yolu, 4. km, dere kenarları, 20150 m, 28.06.2019, Behçet \& Yapar 17000, Avrupa-Sibirya.

\section{A. stolonifera L./ tavusotu}

Alıncak-Aşağıköy arası, bahçe kenarları, $1440 \mathrm{~m}$, 27.07.2019, Behçet \& Yapar 17696, Avrupa-Sibirya.

11. Alopecurus arundinaceus Poir. / kamış tilkikuyruğu

Yelesen köyü yayla yolu, 4. Km, dere kenarları, 2150 m, 28.06.2019, Behçet \& Yapar 17025; Yelesen köyü yaylası, dere kenarı, 2200 m, 21.07.2019, Behçet \& Yapar 17645 Avrupa-Sibirya.

Bingöl'den toplanlan Behcet \& Yapar 17645 nolu A. arundinaceus örnekleri stolon bulundurmaktadir (Şekil 4). Nod sayısı 3-4 adet (Türkiye florasında 2), yaprak aya uzunluğu 22 cm'ye varıyor (Türkiye florasında $2.5-4.5 \mathrm{~cm}$ ).

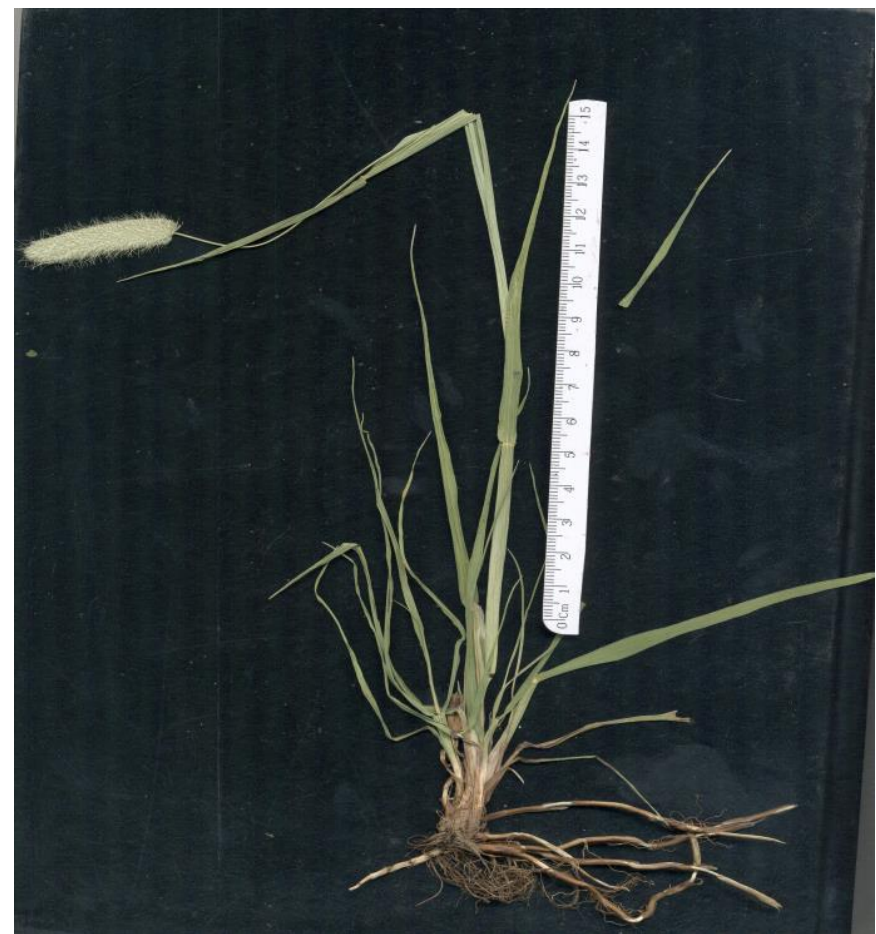

Şekil 4. Alopecuruc arundinaceus örneklerinde stolon yapisi

Figure 4. Stolon structure in Alopecurus arundinaceus specimens

12. A. aucheri Boiss. / kaba tilkikuyruğu

Yelesen köyü batısı, yayla yolu, 3. km, bozkır, 19002000m, 23.06.2018, Behçet \& Yapar 15368a, IranTuran.

13. A. myosuroides Huds. subsp. myosuroides / tarla tilkikuyruğu

Bingöl Üniv. lojmanları çevresi, bozkır, 1100-1150 m, 08.10.2013, Behçet 9160, Avrupa-Sibirya.

14. A. textilis Boiss. subsp. textilis / saçaklı tilkikuyruğu

Yelesen köyü batısı, kayalık-bozkır alanlar, 2166 m, 16.05.2019, Behçet \& Yapar 16509, İran-Turan.

15. Apera intermedia (L.) P.Beauv / puslu ipekçimi
Bingöl merkez, Saray mah, Çapakçur Çayı kenarı, 1100 m, 29.05.2019, Behçet \& Yapar 20154.

16. Arrhenatherum elatius (L.) P.Beauv. ex J.Presl \& C.Pres subsp. elatius / çayır yulafı

Alıncak köyü yolu (Bingöl Mirzan mahallesine giden yol) 3 . km, orman içi, $1400 \mathrm{~m}, 06.06 .2018$, Behçet \& Yapar 15171, Avrupa-Sibirya.

\section{A. kotschyi Boiss. / kısa çayıryulafı}

Alıncak köyüne $2 \mathrm{~km}$ kala (Bingöl Mirzan mahallesine giden yol), bozkır yamaçlar, 1430-1450 m, 06.06.2018, Behçet \& Yapar 15214, İran-Turan.

18. Avena sterilis L. subsp. Iudoviciana (Durieu) Gillet \& Magne / şifan

Bingöl merkez, Saray mah, Çapakçur Çayı kenarı, 1100 m, 29.05.2019, Behçet \& Yapar 20152.

19. Bothriochloa ischaemum (L.) Keng / sakalotu Alıncak-Aşağıköy arası 10. km, orman içi ve açıkları, 1400-1500 m, 07.07.2018, Behçet \& Yapar 15734.

Bitki boyu 120 cm'ye varıyor (Türkiye florasında 30-90 cm), yaprak ölçüleri $25 \mathrm{~cm} x 4.5 \mathrm{~mm}$ 'ye varıyor (Türkiye florasında 7.5-18 cm x 1-2 mm), yaprak ayası uzun piloz tüylü (Türkiye florasında küçük scabriduloz deniyor), infloresansda rasem sayıs 11'e varıyor (Türkiye ve Irak floralarında 2-8)(Şekil 5).

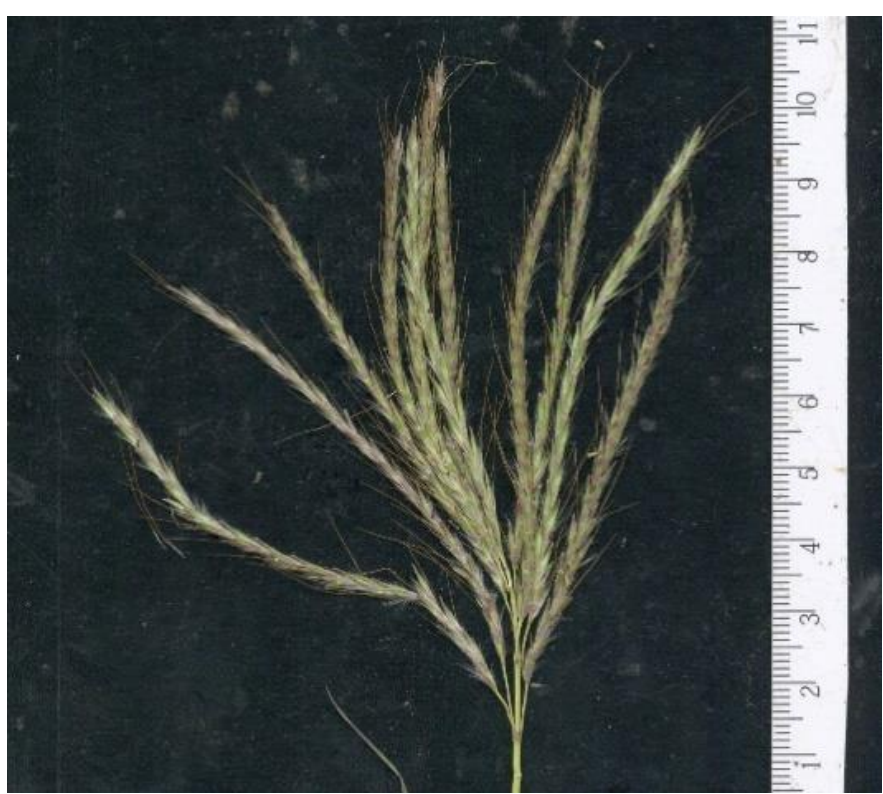

Şekil 5. Bothriochloa ischaemum rasem sayısı

Figure 5. Number of Bothriochloa ischaemum racemes

20. Brachypodium sylvaticum (Huds.) P.Beauv. I koru kılcanı (Şekil 6)

Aşağıköy güney doğusu, vadi içi, bozkır, $1595 \mathrm{~m}$, 05.08.2018, Behçet \& Yapar 16144, Avrupa-Sibirya.

Spikelet sayısı 23'e varıyor (Türkiye florasında 6-12), Rasem boyu 24 cm'ye varıyor (Türkiye florasında 3-20 cm), Gövde bütünü ile geriye dönmüș tüylü (Türkiye florasında sadece nodlar tüylü), Spikelet boyu 45 mm'ye varıyor (Türkiye florasında 15-35 mm), lemma kılçı boyu 27 mm'ye varıyor (Türkiye florasında 7-13 $\mathrm{mm}$ ) 


\section{Briza humilis M. Bieb. / kadındili}

Aşağılköy'e $1 \mathrm{~km}$ kala, yolun solundaki vadi, bozkır, 1600 m, 28.07.2019, Behçet \& Yapar 17747a.

22. Bromus armenus Boiss. / acem kılcanı
Şaban köyü güneyi, kayalık yamaçlar, $2110 \mathrm{~m}$, 12.06.2019, Behçet \& Yapar 16588; Yelesen köyü batısı, bozkır yamaçlar, 2300 m, 28.06.2019, Behçet \& Yapar 17128, end. Iran-Turan.

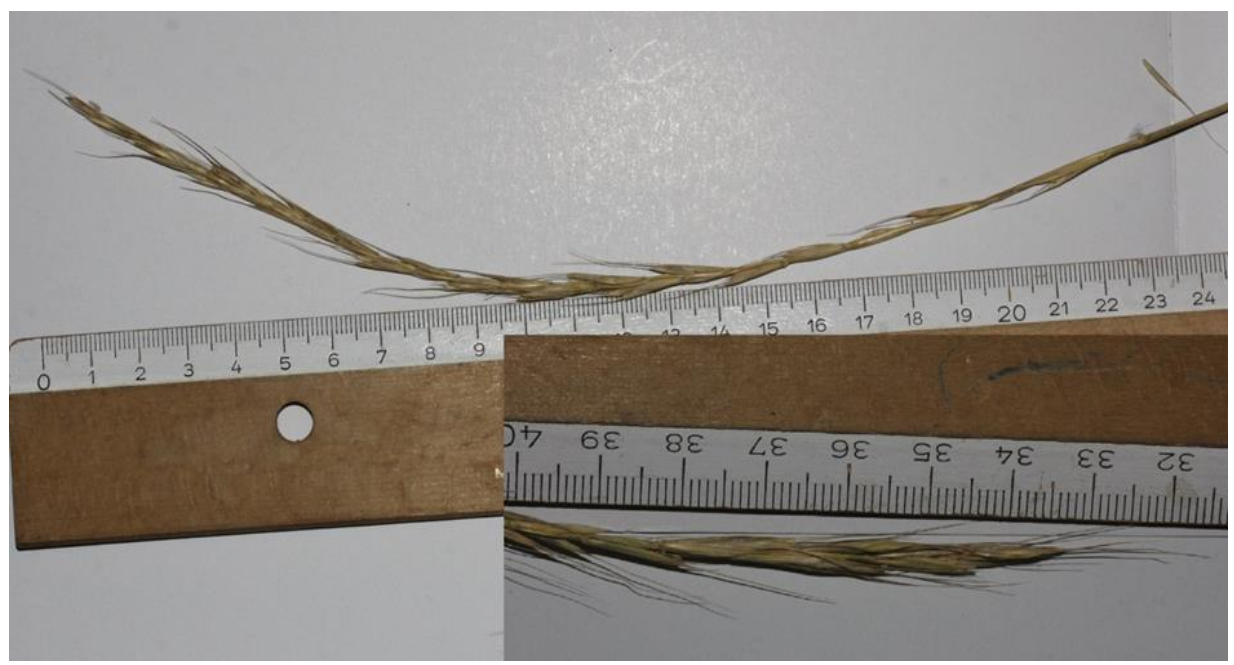

Şekil 6. Brachypodium sylvaticum rasem yapısı

Figure 6. Brachypodium sylvaticum racem structure

\section{B. arvensis L. / tarla kılcanı}

Aşağılköy'e 1-2 km kala, güneye doğru uzanan vadi, orman açıkları, $1480 \mathrm{~m}$, 06.07.2019, Behçet \& Yapar 17270; Bingöl il merkezi doğusu, Çapakçur Vadisi, bozkır, 1044 m, 07.06.2020 Behçet \& Yapar 18393.

Yaprak ölçüleri $30 \mathrm{x} 10 \mathrm{~mm}$ 'ye varıyor (Türkiye florasinda 7-20 x 3-6 mm)

24. B. danthoniae Trin. subsp. danthoniae / ibubukotu

Yelesen köyü batısı, yayla yolu, 3. km, bozkır, 19002000m, 23.06.2018, Behçet \& Yapar 15368; Yelesen köyü doğusu, dere kenarları, 1650 m, 26.06.2014, Behçet 10005.

Spikelet boyu 45 mm'ye varıyor (Türkiye florasında 10$40 \mathrm{~mm}$ ), alt gluma uzunluğu $9.5 \mathrm{~mm}$ 'ye varıyor, üst gluma 12 mm'ye varıyor (Türkiye florasında alt gluma 6-8 mm, üst gluma 7-9 mm), Anter boyu $1.8-2 \mathrm{~mm}$ (Türkiye florasında c.1.5 mm), lemmanın kılçık uzunluğu 21 mm'ye varıyor (Türkiye florasında 5-15 $\mathrm{mm}$ ).

25. B. erectus Huds. / dik brom

Çirişli köyü kuzeyi, bozkır yamaçlar, 1750-1900 m, 31.06.2014, Behçet 9604.

Spikelet boyu $47 \mathrm{~mm}$ 'ye varıyor (Türkiye florasında 15$35 \mathrm{~mm}$ ), lemma boyu $19 \mathrm{~mm}$, kılçık 15 mm'ye varıyor, (Türkiye florasında lemma boyu 10-15, kılçık 3-8 mm). 26. ${ }^{*}$ B. hordeaceus L. subsp. thominii (Hardouin) Maire \& Weiller / kum kılcanı

Topalan köyünün $2 \mathrm{~km}$ güneyi, dere kenarı, 1800-1850 m, 20.06.2017, Behçet 12194, Akdeniz.

$\mathrm{Bu}$ takson ssimdiye kadar Türkiye'de sadece Zonguldak'tan (A3 karesinden) bilinmekteydi.

$27 . \quad B$. japonicus Thunb. subsp. anatolicus (Boiss. \& Heldr.) Penzes / aniyeotu
Bingöl merkez, mezarlık batısı, taş ocağına giderken, 3-4. km,bozkır, $1200 \mathrm{~m}, 25.05 .2013$, Behçet 8780 .

28. B. japonicus Thunb. subsp. japonicus / iyeotu Alıncak köyüne $2 \mathrm{~km}$ kala (Bingöl Mirzan mahallesine giden yol), bozkır yamaçlar, 1430-1450 m, 06.06.2018, Behçet \& Yapar 15213.

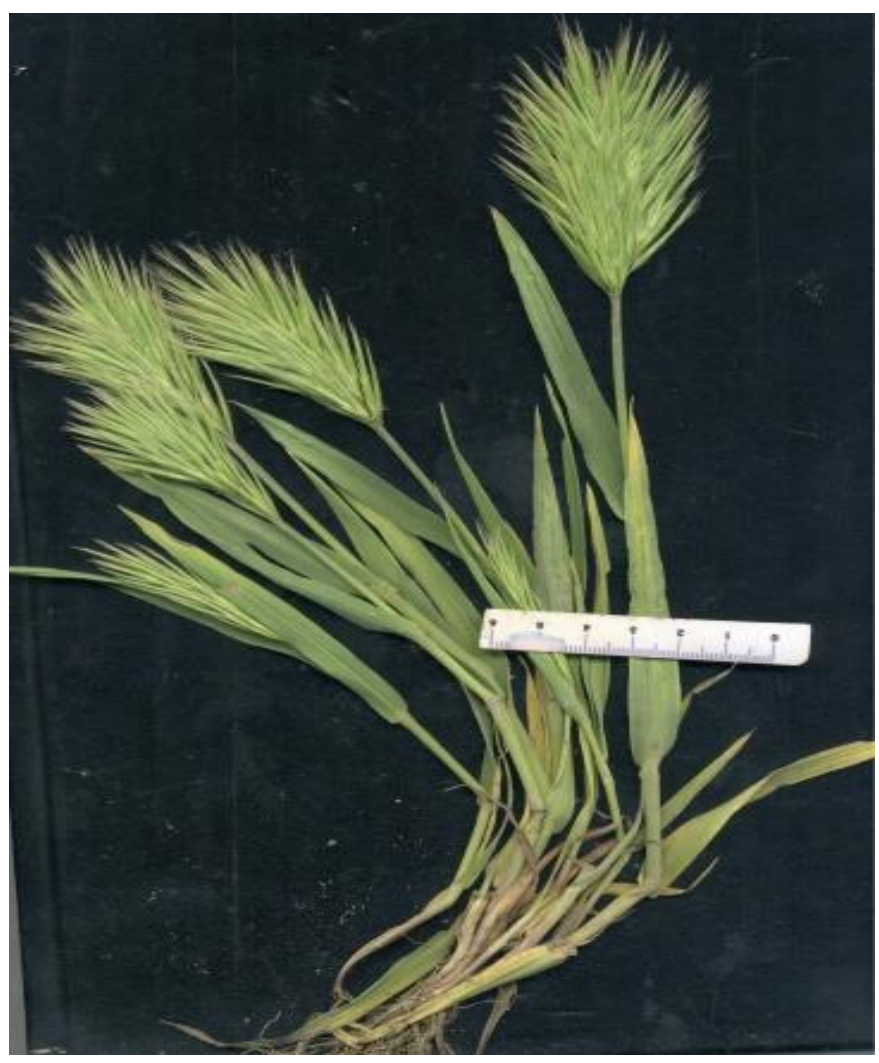

Şekil 7. Bromus pumilio genel görünüş

Figure 7. General view of Bromus pumilio 


\section{B. lanceolatus Roth / kılıç bromu}

Topalan köyü güneyi, orman içi ve açıkları, 1550-1650 m, 09.06.2012, Behçet 7947.

30. *B. pumilio (Trin.) P.M.Sm. / bodur kllcan (Şekil 7)

Şaban köyü kuzeybatısı, bozkır, 1500-1600 m, 30.05.2018, Behçet \& Yapar 15123.

Yaprak genişliği 10 mm'ye varıyor (Türkiye florasında 2-5 mm)

31. B. scoparius L. / ibubuk ekini

Bingöl merkez, mezarlık batısı, taş ocağı yol ayrımı, orman açıları, 1200-1300 m, 22.05.2018, Behçet \& Yapar 15001.

32. B. sterilis L. / sağır ilcan

Bingöl merkez, mezarlık batısı, taş ocağı yol ayrımı, orman açıkları, 1200-1300 m, 22.05.2018, Behçet \& Yapar 15019.

33. B. tectorum L. / kır bromu

Şaban köyü kuzeybatısı, bozkır, 1500-1600 m, 30.05.2018, Behçet \& Yapar 15042.

34. B. tomentellus Boiss. subsp. tomentellus / bozkır bromu

Yelesen köyü batısı, yayla yolu, 3. km, bozkır, 19002000m, 23.06.2018, Behçet \& Yapar 15382, İranTuran.

35. Calamagrostis epigejos (L.) Roth / bekarotu Alıncak-Aşağıköy arası 10. km, dere kenarı, $1410 \mathrm{~m}$, 08.07.2018, Behçet \& Yapar 15799, Avrupa-Sibirya.

36. C. pseudophragmites (Haller f.) Koeler / sazçimi

Yelesen köyü batısı, yayla yolu, 4-5. km, yol kenarı, nemli alanlar, $2150 \mathrm{~m}, 02.07 .2018$, Behçet \& Yapar 15669, Avrupa-Sibirya.

37. Catabrosa aquatica (L.) P.Beauv. / çipil

Alıncak köyü, yol kenarı, nemli alan, $1350 \mathrm{~m}$, 06.06.2018, Behçet \& Yapar 15270; Yelesen köyü batısı, yayla yolu, 4. km, dere kenarı, $2050 \mathrm{~m}$, 02.07.2018, Behçet \& Yapar 15586.

Panikula $32 \mathrm{~cm}$ uzunluğunda (Türkiye florasında (5-) 7-23(-26) cm).

38. Crypsis acuminata Trin. subsp. acuminata / sivri bakakotu

Üçyaka-Balpınar (Metan) köyleri arası, Haziran köyü yol ayrımı, bozkır, 1840 m, 08.08.2018, Behçet \& Yapar 16242.

39. C. acuminata Trin. subsp. borszczowii (Regel) Kit Tan /sivri bakakotu (Şekil 8)

Ortaköy kuzeyi, nemli yerler, 1559 m, 14.07.2020, Behçet \& Yapar 18930, İran-Turan.

40. C. alopecuroides (Piller \& Mitterp.) Schard. / dere bakakotu

Balpınarı eski köy yolu, 1. km, yol kenarı, $1770 \mathrm{~m}$, 29.08.2019, Behçet \& Yapar 18027.

41. C. schenoides (L.) Lam. /bakakotu

Bingöl merkez, mezarlık batısı, yol kenarları, 11501200 m, 19.07.2020, Behçet \& Yapar 18990.

Paleada damar belli değil (Türkiye florasında 2 damarl deniyor)

42. Cynodon dactylon (L.) Pers var. villosus Regel / köpekdişi

Aşağı köy güney doğusu, vadi, bozkır, 1595 m, 05.08.2018, Behçet \& Yapar 16174.

43. $\quad{ }^{*}$ Cynosurus cristatus L. / tarakotu

Yelesen köyü batısı, yayla yolu, 4. km, dere kenarı, 2050 m, 02.07.2018, Behçet \& Yapar 15567, AvrupaSibirya.

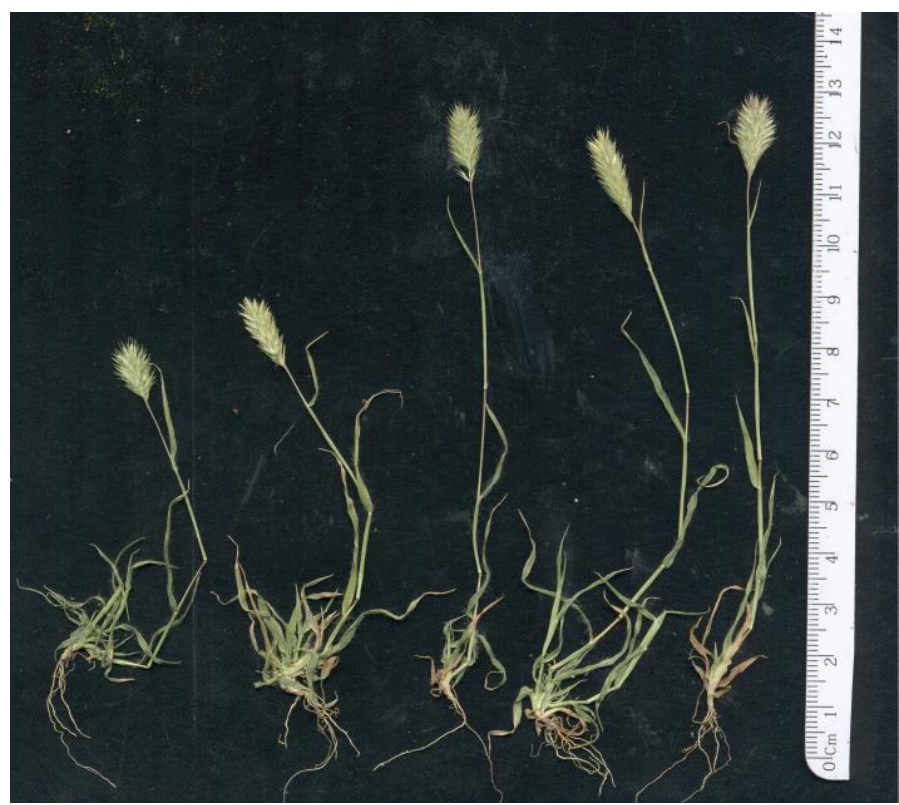

Şekil 8. Crypsis acuminata subsp. borszczowii genel görünüm

Figure 8. Crypsis acuminata subsp. borszczowii general view

44. Dactylis glomerata L. subsp. hispanica (Roth) Nyman / kıllı domuzayrığı

Şaban köyü kuzeybatısı, bozkır, 1500-1600 m, 30.05.2018, Behçet \& Yapar 15059.

45. Deschampsia caespitosa (L.) P.Beauv. / çayırsaçı

Yelesen köyü batısı, yayla yolu, 2. km, çayır, $1925 \mathrm{~m}$, 23.06.2018, Behçet \& Yapar 15426.

46. Digitaria sanguinalis (L.) Scop. / kızıl çatalotu Bingöl Üniv. lojmanları çevresi, nemli alan, 1100-1150 m, 08.10.2013, Behçet 9170;

Bingöl, Uydukent mah., yol ve bahçe kenarları, 1150 m, 05.07.2020, Behçet \& Yapar 19087

Bitki boyu 118 cm'ye varıyor (Türkiye florasında 20-60 $\mathrm{cm}$ ), yaprak genişliği $13 \mathrm{~mm}$ (Türkiye florasında 9 mm'ye variyor). Rasem boyu $19.5 \mathrm{~cm}$ ye varıyor (Türkiye florasında $3-15 \mathrm{~cm}$ deniyor), Rasem sayısı 710 adet (Türkiye florasında 3-7)

47. Echinaria capitata (L.) Desf. / dikenbaşotu

Şaban köyü kuzeybatısı, bozkır, 1500-1600 m, 30.05.2018, Behçet \& Yapar 15078a.

48. Echinochloa crus-galli (L.) P.Beauv. / darıcan Aşağı köy güney doğusu, dere kenarları, 1462 m, 
05.08.2018, Behçet \& Yapar 16184, Bingöl Üniv. lojmanları çevresi, nemli alan, 1100-1150 m, 08.10.2013, Behçet 9161.

49. $E$. chinochloa oryzoides (Ard.) Fritsch / kara cinek

Bingöl, Uydukent mah., yol ve bahçe kenarları, 1150 m, 28.07.2020, Behçet \& Yapar 19088.

50. *Eleusine indica (L.) Gaertner / kazotu

Bingöl, Uydukent mah., yol ve bahçe kenarları, 1150 m, 18.08.2019, Behçet \& Yapar 18055, Bingöl Üniv. lojman çevreleri, nemli alan, 1100-11500 m, 06.11.2013, Behçet 9281.

51. Elymus elongatiformis (Drobow) Assadi / tarla ayrığı

Alıncak köyüne $1 \mathrm{~km}$ kala (Bingöl, Mirzan mahallesine giden yol), orman açıkları, 1350-1400 m, 06.06.2018, Behçet \& Yapar 15249, Iran-Turan.

52. ${ }^{*} E$. elongatus (Host) Runemark subsp. elongatus / putaotu

Aşağıköy güneyi, vadi, nemli dere kenarları, $1400 \mathrm{~m}$, 20.07.2020, Behçet \& Yapar 19040.

53. *E. elongatus (Host) Runemark subsp. ponticus (Podp.) Melderis / çayırputası

Yelesen köyü güneyi, çayır, ekili alan çevresi, $1825 \mathrm{~m}$, 11.08.2018, Behçet \& Yapar 16360.

54. *E. elongatus (Host) Runemark subsp. salsus Melderis / çorak putaotu

Ortaköy kuzeyi, bozkır, 1600 m, 15.07.2020, Behçet \& Yapar 18944, end.

Sadece Kayseri'den biliniyor (B4-B5)

55. $\quad \boldsymbol{E}$. elongatus (Host) Runemark subsp. turcicus (McGuire) Melderis / puslu putaotu

Şaban köyü kuzeybatısı, bozkır, 1500-1600 m, 30.05.2018, Behçet \& Yapar 15078; Yelesen köyü cami doğusu, bahçe kenarı, 1805 m, 02.07.2018, Behçet \& Yapar 15713.

56. $\quad * E$. erosiglumis Melderis / özge buğday

Alıncak köyü güneyi, orman açıkları, 1440 m, 15.07.2018, Behçet \& Yapar 15848, end. İran-Turan.

57. $\boldsymbol{E}$. hispidus (Opiz) Melderis subsp. barbulatus (Schur) Melderis / llamuk

Yelesen köyü batısı, yayla yolu, 3. km, bozkır, 19002000m, 23.06.2018, Behçet \& Yapar 15366.

58. $\quad$ E. hispidus (Opiz) Melderis subsp. hispidus / elimotu

Yelesen köyü batısı, yayla yolu, 5-6. km, yol ayrımı, bozkır, 2060 m, 02.07.2018, Behçet \& Yapar 15520.

Yaprak aya genişliği $9 \mathrm{~mm}$ (Türkiye florasında 2-6 mm).

59. ${ }^{*} \boldsymbol{E}$. hispidus (Opiz) Melderis subsp. podpyerae (Nabelek) Melderis / gavur elimotu

Aşağı köye 1-2 km kala, vadi içi, orman açıkları, 1480 m, 06.07.2019, Behçet \& Yapar 17269.

60. $\quad \boldsymbol{E}$. panormitanus (Parl.) Tzvelev / koru buğdayı Alıncak köy yolu (Bingöl Mirzan mahallesine giden yol), 3. km, orman içi, $1400 \mathrm{~m}, 06.06 .2018$, Behçet \& Yapar 15172, Akdeniz.

61. E. repens (L.) Gould / sabankıran
Şaban köyü yayla yolu, 2. km, çayır alanlar, $2071 \mathrm{~m}$, 19.07.2018, Behçet \& Yapar 16041.

62. *E. transhyrcanus (Nevski) Tzvelev / geliç

Şaban köyü yaylası doğusu, nemli yamaçlar, $2176 \mathrm{~m}$, 18.07.2018, Behçet \& Yapar 15931.

Erzurum (A8) ve Hakkari (C10) illerinden yayılışı biliniyor.

63. *Eragrostis barrelieri Daveau /salkım yulaf

Bingöl merkez, eski otogar doğusu, yol kenarları, 1112 m, 05.08.2020, Behçet \& Yapar 19104

64. $\quad \boldsymbol{E}$. minor Host / bodur yulaf

Bingöl merkez, Bahçelievler mahallesi, yol kenarı, 1186m, 29.08.2019, Behçet \& Yapar 18050.

65. $\quad \boldsymbol{E}$. pilosa (L.) P.Beauv. / killı yulaf

Bingöl Üniv. Fen-Edebiyat Fakültesi önü, nemli alan, 1100-1150 m, 09.07.2013, Behçet 9083, Bingöl Üniv. kampüsü, nemli alan, 1100-1150 m, 11.09.2017, Behçet 12455 .

Bitki boyu 75 cm'ye varıyor (Türkiye florasında 8-50 cm), panikula branşları skabrit (Türkiye florasında skabrit değil-düz), yaprak aya boyu 19 cm'ye varıyor (Türkiye florasında $15 \mathrm{~cm}$ 'ye varıyor).

66. Eromopoa altaica (Trin.) Roshev. / dağ salkımı Üçyaka-Balpınarı köyleri arası, 3-4. km, vadi içi, nemli alan, 1800 m, 23.06.2019, Behçet \& Yapar 16942, İran-Turan.

67. $E$. multiradiata (Trautv.) Roshev. / dere salkımı

Alıncak-Aşağıköy arası $10 . \mathrm{km}$, yolun solundaki vadi, orman içi ve açıkları, 1578 m, 13.07.2019, Behçet \& Yapar 17377, İran-Turan.

68. *Festuca adanensis Markgr. /adana yumağ Bingö merkez, Uydukent mah., yol ve bahçe kenarları, 1150 m, 05.07.2020, Behçet \& Yapar 18897, end.

69. $\boldsymbol{F}$. arundinaceae Schreb. subsp. arundinaceae / kamış yumağı

Bingöl Üniv. lojmanları çevresi, nemli alan, 1100-1150 m, 18.11.2013, Behçet 9308 .

70. $\boldsymbol{F}$. brunnescens (Tzvelev) Galushko / esmer yumak

Yelesen köyü batısı, güneye bakan bozkır yamaçlar, 2350m, 28.06.2019, Behçet \& Yapar 17069, IranTuran.

71. F. chalcophaea Krecz. \& Bobrov subsp. chalcophaea / çayır yumağ

Şaban köyü güneyi, 3-4. km, bozkır yamaçlar $2110 \mathrm{~m}$, 12.06.2019, Behçet \& Yapar 16566, İran-Turan.

72. ${ }^{*} \boldsymbol{F}$. gigantea (L.) Vill. / koca yumak

Alıncak-Aşağıköy arası, 10 . km, orman içi ve açıkları, 1400-1500 m, 07.07.2018, Behçet \& Yapar 15724, Avrupa-Sibirya.

73. $\quad \boldsymbol{F}$. pratensis Huds. / çayır yumağ

Aşağı köye 1-2 km kala, güneye doğru uzanan vadi, dere kenarları, 1450 m, 06.07.2019, Behçet \& Yapar 17234 .

74. Gaudiniopsis macra (M.Bieb.) Eig var. macra/ som yulaf

Bingöl merkez, Mirzan mahallesine giderken, Alıncak 
köyü yol ayrımı, orman açıkları, 1400-1450 m, 06.06.2018, Behçet \& Yapar 15264; Bingöl merkez, Çapakçur Vadisi, dere kenarları, 1100 m, 12.05.2020, Behçet \& Yapar 1817, İran-Turan.

Örnekte üst gluma 3 damarl (Türkiye ve Irak floralarinda 5 damarl deniyor, Avrupa ve Rusya floralarında 3-5 olabildiği belirtiliyor)

75. Glyceria notata Chevall / kıvrık tatlıçim

Orta köy güneyi, dere kenarları, 1615 m, 31.07.2019, Behçet \& Yapar 17805.

76. Helictotrichon planiculme (Schrad.) Pilg. / cimil yulaf

Yelesen köyü batısı, yayla yolu, 5-6. km, yol ayrımı, bozkır, 2060 m, 02.07.2018, Behçet \& Yapar 15507; Aşağıköy-Ortaköy arası, orman açıkları, $1680 \mathrm{~m}$, 16.06.2020, Behçet \& Yapar 18514 Avrupa-Sibirya.

Gövde tabanda yuvarlak (Türkiye florasında basık), Nod sayıs1 1-3 adet (Türkiye florasında genellikle 1), Yaprak aya uzunluğu $40 \mathrm{~cm}$ 'ye varıyor (Türkiye florasında 4-27 cm), spikelet yeşil renkli (Türkiye florasinda kahverengi veya menekse)

77. $\quad H$. pratense (L.) Pilg. / yamaç yulafı

Yelesen köyü batısı, yayla yolu, 3. km, bozkır, 19002000m, 23.06.2018, Behçet \& Yapar 15381, AvrupaSibirya.

78. Heteranthelium piliferum (Sol.) Hochst. ex Jaub. \& Spach / çorak arpası

Şaban köyü kuzeybatısı, bozkır, 1500-1600 m, 30.05.2018, Behçet \& Yapar 15125, İran-Turan.

79. Hordeum bulbosum L. / boncuk arpa

Şaban köyü kuzeybatısı, bozkır, 1500-1600 m, 30.05.2018, Behçet \& Yapar 15112.

80. ${ }^{*} H$. distichon L. / ikili arpa

Bingöl merkez, Çapakçur Vadisi, yürüyüş yolu, yamaçlar, 1050-1100 m, 04.06.2014, Behçet 9682, kültür.

\section{1. $\quad H$. geniculatum All. / yatık arpa}

Ortaköy kuzeyi, nemli alanlar, 1559 m, 15.07.2020,

Behçet \& Yapar 18934, Avrupa-Sibirya.

82. H. murinum L. subsp. glaucum (Staud.) Tzvelev / duvar arpası

Bingöl Üniv., Fen-Edebiyat Fakültesi önü, nemli alan, 1100-1150 m, Behçet 7718.

83. $H$. murinum L. subsp. leporinum (Link) Arcang. /kılçık arpa

Bingöl merkez, eski otogar doğusu, yol kenarları, 1112 m, 02.06.2020, Behçet \& Yapar 18365, Irran-Turan.

84. $H$. vulgare L. /arpa

Bingöl merkez doğusu, Çapakçur Vadisi, bozkır, 1044 m, 07.06.2020, Behçet \& Yapar 18391, kültür.

85. Koeleria pyramidata (Lam.) P.Beauv. / kırnal

Yelesen köyü batısı, yayla yolu, 5-6. km, yol ayrımı, bozkır, 2060 m, 02.07.2018, Behçet \& Yapar 15521, Avrupa-Sibirya.

86. Lolium multiflorum Lam. / İtalyan çimi

Bingöl Üniv. lojmanları çevresi, nemli alan, 1100-1150 m, 18.11.2013, Behçet 9307.

87. L. persicum Boiss. \& Hohen. / eres çimi
Bingöl Üniv. lojmanları çevresi, nemli alan, 1100-1150 m, 08.10.2013, Behçet 9177, İran-Turan.

88. L. rigidum Gaudich var. rigidum / sert çim Bingöl merkez, Bahçelievler mahallesi batısı, bozkır, 1200-1300 m, 10.05.2014. Behçet 9452.

89. ${ }^{*}$ L. temulentum L. var. temulentum/delice çim Bingöl merkez doğusu, Çapakçur Vadisi, yol kenarı, bozkır, 1044 m, 07.06.2020 Behçet \& Yapar 18411.

90. Melica persica Kunth subsp. jacquemontii (Decne. ex Jacquem.) P.H.Davis / çayır inciotu

Alıncak köyüne $2 \mathrm{~km}$ kala (Bingöl Mirzan mahahellesine giden yol), bozkır yamaçlar, 1430-1450 m, 06.06.2018, Behçet \& Yapar 15219, Iran-Turan.

91. Milium vernale M.Bieb. subsp. montianum (Parl.) Trab. / yayla darısı (Şekil 9) Alıncak köyüne $1 \mathrm{~km}$ kala (Bingöl Mirzan mahahellesine giden yol), orman açıkları, 1350-1400 m, 06.06.2018, Behçet \& Yapar 15248, Akdeniz.

Ligula uzunluğu $8 \mathrm{~mm}$ 'ye varıyor (Türkiye florasında 2-4 mm), anter boyu $2.3 \mathrm{~mm}$ (Türkiye florasında 1.3 $1.8 \mathrm{~mm}$ ), spikelet boyu 3.7 mm'ye varıyor (Türkiye florasında 3-3.3 mm), panikula branşları $8.8 \mathrm{~cm}$ 'ye varıyor (Türkiye florasında $3-7 \mathrm{~cm}$, Irak Florasında 4$11 \mathrm{~cm}$ ), yaprak aya uzunluğu (leaf blades) $12.7 \mathrm{~cm}$ 'ye varıyor (Türkiye florasında $2-7 \mathrm{~cm}$ )

92. Nardus stricta L. / kılotu

Yelesen köyü batısı, bozkır yamaçlar, 2350m, 28.06.2019, Behçet \& Yapar 17069a.

93. Oryzopsis holciforme (M.Bieb.) Hack. subsp. holciforme var. holciforme / kadife pirinçotu

Alıncak köy yolu (Bingöl Mirzan mahahellesine giden yol) 3 . km, orman içi, $1400 \mathrm{~m}, 06.06 .2018$, Behçet \& Yapar 15170 .

94. Panicum miliaceum L. /darı

Bingöl merkez, Uydukent mah, yol ve bahçe kenarları, 1150 m, 05.07.2020, Behçet \& Yapar 18900, kültür.

95. *Paspalum distichum L. / yalan darısı

Bingöl üniv. Lojmanları çevresi, nemli alan, 1100-1150 m, 08.10.2013, Behçet 9171.

96. Phalaris arundinaceae L. / kanyaş

Orta köy güneyi, dere kenarları, 1615 m, 31.07.2019, Behçet \& Yapar 17805a.

97. * $P$. canariensis L. /kuş yemi (Şekil 10)

Bingöl merkez, Uydukent mah., yol ve bahçe kenarları, 1150 m, 05.07.2020, Behçet \& Yapar 18898, Akdeniz.

98. Phleum alpinum L. / alp itkuyruğu

Yelesen köyü batısı, yayla yolu, 4-5 km, yol kenarı, nemli alanlar, 2150 m, 02.07.2018, Behçet \& Yapar 15665 .

99. $\quad \boldsymbol{P}$. boissieri Bornm. / yayla itkuyruğu

Bingöl merkez, Saray mah., Çapakçur Çayı kenarı, 1100 m, 29.05.2019, Behçet \& Yapar 20155, İranTuran.

100. $\quad \boldsymbol{P}$. montanum K.Koch subsp. montanum / dağ itkuyruğu

Şaban köyü kuzeybatısı, bozkır, 1500-1600 m, 30.05.2018, Behçet \& Yapar 15062; Yelesen köyü 
batısı, bozkır yamaçlar, 2350m, 28.06.2019, Behçet \& Yapar 17134.

101. $\boldsymbol{P}$ montanum K. Koch. subsp. serrulatum (Boiss.) Dogan / dişlek itkuyruğu Yelesen köyü batısı, yayla yolu, 5. km, yamaçlar, bozkır, 2118 m, 02.07.2018, Behçet \& Yapar 15624. 102. *P. paniculatum Huds. subsp. ciliatum (Boiss.) Doğan / salkım itkuyruğu

Bingöl Üniv. kampüsü, nemli alan, $1150 \mathrm{~m}$, 11.04.2018, Behçet 12610, İran-Turan.

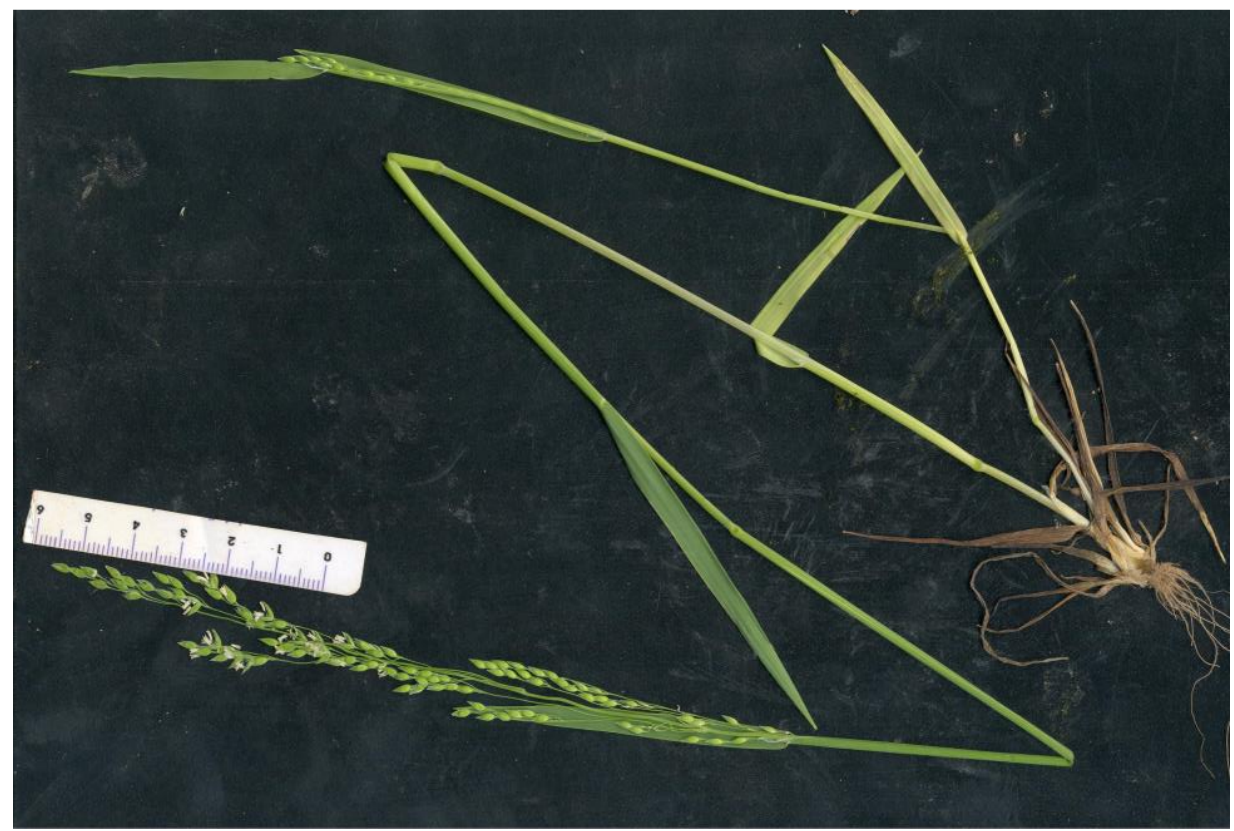

Şekil 9. Milium vernale subsp. montianum genel görünüşü Figure 9. Milium vernale subsp. montianum general view

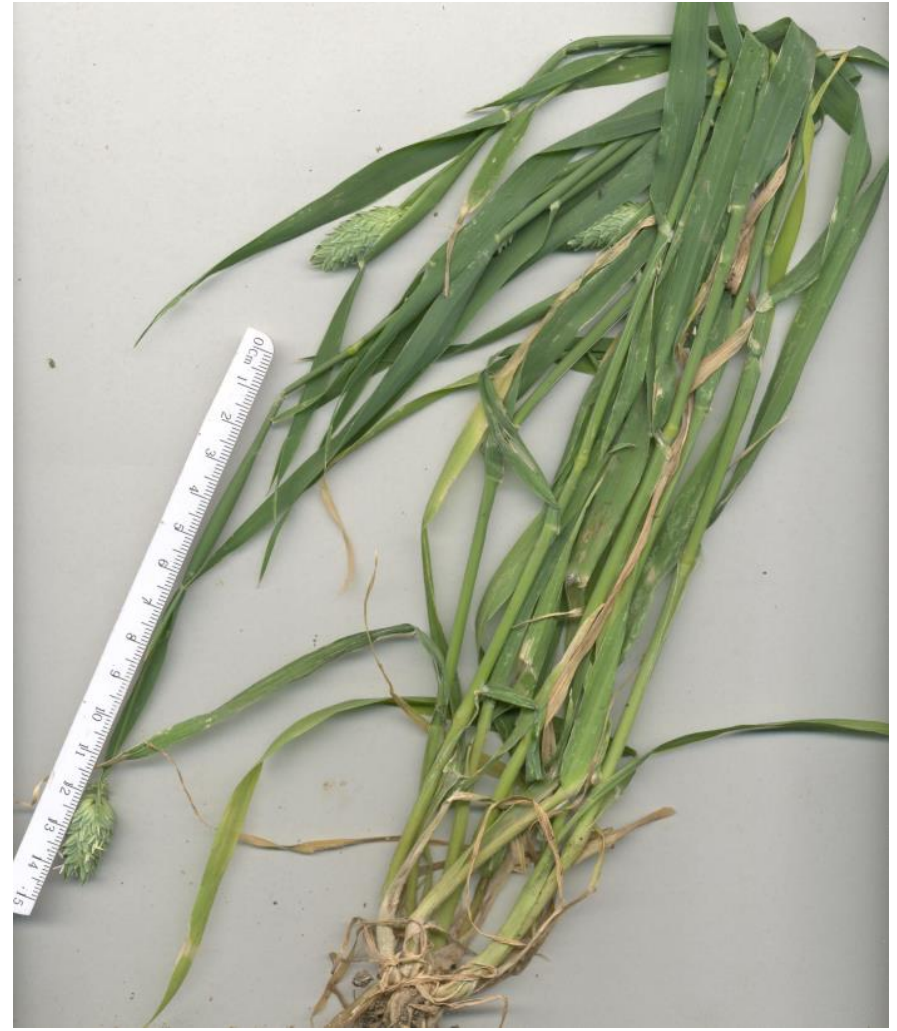

Şekil 10. Phalaris canariensis

Figure 10. Phalaris canariensis

103. P. pratense L. / çayır itkuyruğu

Şaban köyü yaylasına $1 \mathrm{~km}$ kala, nemli alan, $2117 \mathrm{~m}$,
19.07.2018, Behçet \& Yapar 16020, Avrupa-Sibirya.

Panikula uzunluğu 14 cm'ye varıyor (Türkiye florasinda 1-6.2(-11) cm).

104. Phragmites australis (Cev.) Trin. ex Steud. I kamış

Orta köy güneyi, dere kenarları, 1615 m, 31.07.2019, Behçet \& Yapar 17807a.

105. Pilgerochloa major (H.Scholz) Doğan \& Behçet Bingöl merkez, mezarlık batısı, taş ocağ 1 yolu, $3-4$. km bozkır, 1200 m, 25.05.2013, Behçet 8814a, end.

106. Poa angustifolia L. / dar salkımotu

Bingöl batısı, Mendo tesisleri güneyi, dere kenarı, 1250-1350 m, 30.05.2015, Behçet 10543.

107. P. annua L. / salkımotu

Yelesen köyü batısı, yayla yolu, 4-5 km, yol kenarı, nemli alanlar, $2150 \mathrm{~m}, 02.07 .2018$, Behçet \& Yapar 15649 .

108. P. cenisia All. / uslu salkım

Üçyaka köyü yolu, 3-4. km, bozkır, 1300-1400 m, 10.05.2014, Behçet 9511.

109. P. longifolia Trin. / ipek salkımotu

Yelesen köyü doğusu, dere kenarları,1650 m, 26.06.2014, Behçet 10005, Avrupa-Sibirya.

110. $\quad P$. nemoralis L. / orman salkımotu

Alıncak köyü girişi, yol kenarı, 1320 m, 06.06.2018, Behçet \& Yapar 15291.

111. P. pratensis L. / çayır salkımotu (Şekil 11)

Alıncak köyüne $1 \mathrm{~km}$ kala (Bingöl Mirzan mahahellesine giden yol), orman açıları, 1350-1400 
m, 06.06.2018, Behçet \& Yapar 15247, Bingöl merkez, Çapakçur Vadisi, dere kenarları, 1100 m, 12.05.2020, Behçet \& Yapar 18171

Örnekte çiçeksiz sürgün var ve her bir çiçeksiz sürgün 2-3 yapraklı (Türkiye florasında çiçeksiz sürgün yok). Bitkide hem rizom hem de stolon var (Türkiye florasinda rizom var, Rusya florasinda stolon var deniyor).

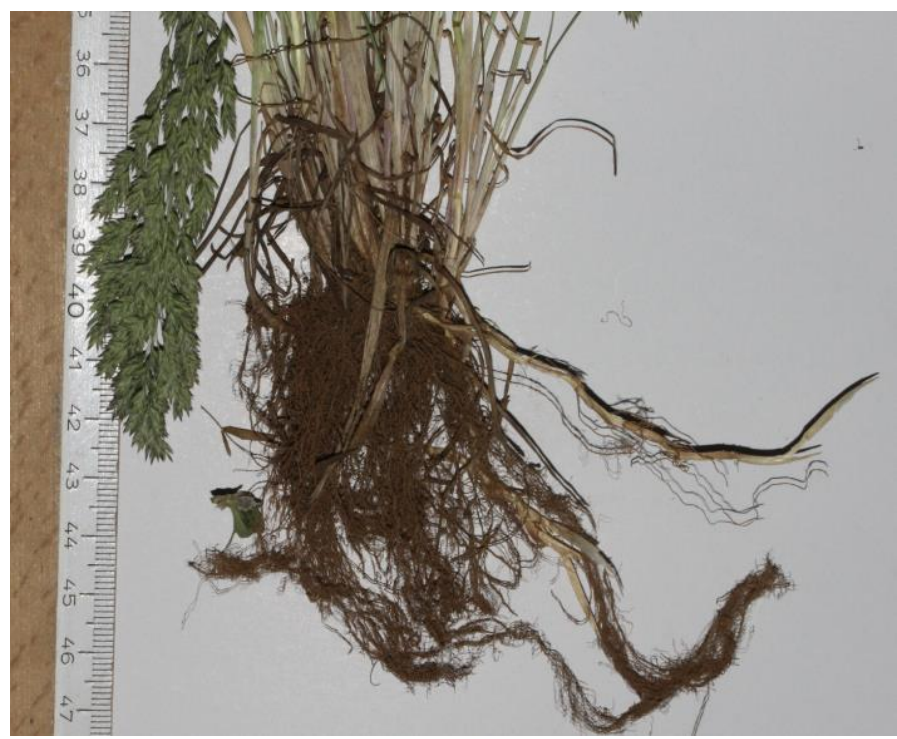

Şekil 11. Poa pratensis stolon yapısı

Figure 11. Poa pratensis stolon structure

112. $\quad{ }^{*} P$. sterilis M.Bieb. / köse salkımotu

Alıncak köyüne $2 \mathrm{~km}$ kala, bahçe kenarları, 1300-1350 m, 06.06.2018, Behçet \& Yapar 15283.

113. $\boldsymbol{P}$. timoleontis Heldr. ex Bornm. / gür salkımotu Topalan-Çirişli köyleri arası, meşe açıklıkları, 15301600 m, 08.05.2012, Behçet 7630. Doğu Akdeniz.

Yaprak ayası $2 \mathrm{~mm}$ genişliğinde (Türkiye florasında 0.3-1 $\mathrm{mm}$ ).

114. P. trivialis L. / kaba salkımotu

Bingöl merkez, mezarlık batısı, taş ocağı yol ayrımı, orman açıkları, 1200-1300 m, 22.05.2018, Behçet \& Yapar 15005; Yelesen köyü batısı, yayla yolu, 2. km, çayır, 1925 m, 23.06.2018, Behçet \& Yapar 15418.

Örnekte rizom tesbih görünümünde boğumlu yapıdadir (Türkiye florasında bu yapıdan bahsedilmiyor) (Şekil 12).

115. *Polypogon monspeliensis (L.) Desf. / hitır Bingöl merkez mezarlık güneyi bozkır yamaçlar, 1150 m, 16.08.2011, Behçet 7345.

116. Psathyrostachys fragilis (Boiss.) Nevski subsp. secaliformis Tzvelev / çavdar arpası

Şaban köyü güneyi, 3-4. km, bozkır yamaçlar $2110 \mathrm{~m}$, 12.06.2019, Behçet \& Yapar 16574, end. İran-Turan.

117. $\quad P$. fragilis (Boiss.) Nevski subsp. villosus Baden / tüylü arpa

Şaban köyü kuzeybatısı, bozkır, 1500-1600 m, 30.05.2018, Behçet \& Yapar 15106, İran-Turan.

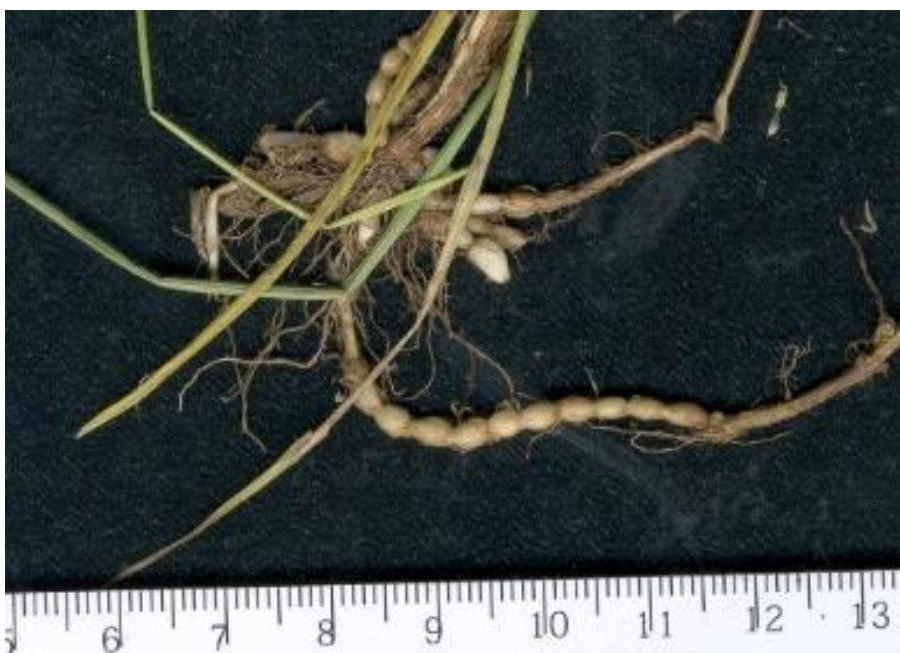

Şekil 12. Poa trivialis rizom yapısı

Figure 12.Poa trivialis rhizome structure

118. Pseudophleum anatolicum Doğan, Behçet \& A. Sinan / anadolu efeotu

Bingöl il merkezi, mezarlık batısı, 2-3. km, taş ocağı çevresi, bozkır yamaçlar, 1150-1200 m, 25.05.2013, Behçet 8703, end.

119. Psilurus incurvus ( Gouan) Schinz \& Thell. / eğri kuyrukotu

Bingöl Üniv. Fen-Edebiyat Fakültesi önü, nemli alan, 1100-1150 m, Behçet 7704.

120. Rostraria berythea (Boiss. \&Blanche) Holub / maraş gagaotu

Bingöl merkez, Karşıyaka mah., cami çevresi, 11001200 m, 15.05.2013, Behçet 8689b.

121. R. cristata (L.) Tezvelev var. cristata / gagaotu Bingöl merkez, Yeni mah., yol ve bahçe kenarı, 12001300 m, 27.05.2018, Behçet 12714 .

122. Sclerochloa dura (L.) P. Beauv. / micirotu

Bingöl merkez, Karşıyaka mah., yol kenarları, 1150 m, 09.04.2016, Behçet 11082, Avrupa-Sibirya.

123. Secale anatolicum Boiss. / anadolu çavdarı

Balpınarı köyü eski yol ayrımını geçtikten sonra, bozkır yamaçlar, 1950 m, 22.06.2019, Behçet \& Yapar 16732; Aşağıköy-Ortaköy arası, orman açıkları, 1680 m, 16.06.2020, Behçet \& Yapar 18506.

Örnekte spika uzunluğu 12 cm'ye (Türkiye florasında 4-8 cm), anter uzunluğu 6-7 mm kadar çııyor (Türkiye florasinda $5 \mathrm{~mm}$ )

124. S. cereale L. subsp. ancestrale Zhuk. / tüylü çavdar

Şaban köyü yaylasına $1 \mathrm{~km}$ kala, bozkır, $2125 \mathrm{~m}$, 19.07.2018, Behçet \& Yapar 16033, end.

125. S. cereale L. subsp. cereale / çavdar

Bingöl Üniv. Mühendislik Fakültesi önü, ekili alan, 1150 m, 29.05.2018, Behçet 12723.

126. S. ciliatoglume (Boiss.) Grossh. / acem çavdarı Yelesen köyü batısı, yayla yolu, 5. km, tepe yamaçları, bozkır, 2118 m, 02.07.2018, Behçet \& Yapar 15610, İran-Turan. 
Örneklerde anter boyu 8.5-8.7 mm'ye (Türkiye florasinda c. $5 \mathrm{~mm}$ ), gluma boyu alt çiçeklerde 7-8 mm'ye, üst çiçeklerde 13 mm'ye kadar çıkıyor (Türkiye florasinda 10-11 mm).

127. S. montanum Guss. / dağ çavdarı

Yelesen köyü batısı, yayla yolu, 4. km, yolun sağındaki çayır, dere kenarı, 2050 m, 02.07.2018, Behçet \& Yapar 15591.

128. S. vavilovii Grossh. /gevrek çavdar

İl merekzi doğusu, Çapakçur Vadisi, bozkır, 1044 m, 07.06.2020, Behçet \& Yapar 18411.

129. Setaria glauca (L.) P. Beauv. / sıçansaçı

Bingöl merkez, sanayi sitesi çevresi, nemli alan, 10001050 m, 01.09.2012, Behçet 8272 .

130. S. verticillata (L.) P. Beauv. var. ambigua (Guss.) Parl. / Arnavut darisı

Aşağı köy güneydoğusu, dere kenarları, $1462 \mathrm{~m}$, 05.08.2018, Behçet \& Yapar 16182.

131. S. viridis (L.) P. Beauv. / yeşil sıçansaçı

Bingöl Üniv. lojmanları çevresi, nemli alan, 1100-1150 m, 08.10.2013, Behçet 9164a.

132. Sorghum halepense (L.) Pers. var. halepense / ekin süpürgesi

Bingöl Üniv. lojmanları çevresi, nemli alan, 1100-1150 m, 08.10.2013, Behçet 9164 .

133. *Stipa bromoides (L.) Dörfl. / kılaç

Bingöl merkez, mezarlık batısı, 2 . km taş ocağı çevresi, bozkır, 1200-1300 m, 10.08.2014, Behçet 10288, Akdeniz.

134. S. ehrenbergiana Trin. \& Rupr. / sorguçotu

Yelesen köyü batısı, bozkır yamaçlar, 2350m, 28.06.2019, Behçet \& Yapar 17132.

135. S. holosericea Trin. /dirgen kılaç

Yelesen köyü batısı, yayla yolu, 4. km, bozkır, $1975 \mathrm{~m}$, 23.06.2018, Behçet \& Yapar 15472, İran-Turan.

136. *S. lessingiana Trin. \& Rupr. / gevşek sorguçotu

Yelesen köyü batısı, yayla yolu, 4-5 km, yol kenarı, bozkır, 2140 m, 02.07.2018, Behçet \& Yapar 15689.

137. ${ }^{*}$ S. pulcherrima K. Koch subsp. crassiculumis (P.A.Smirn.) Tzvelev / kaba sorguç

Aşağıköy'e $1 \mathrm{~km}$ kala, vadi içi, bozkır, $1600 \mathrm{~m}$, 28.07.2019, Behçet \& Yapar 17715a.

138. Taeniatherum caput-medusae (L.) Nevski subsp. crinitum (Schreb.) Melderis / kılaç arpası

Bingöl Üniv. Fen-Edebiyat Fakültesi önü, nemli alan, 1100-1150 m, Behçet 7702 .

139. Trisetum flavescens (L.) P.Beauv. / palah

Yelesen köyü batısı, yayla yolu, 3. km, bozkır, 19002000m, 23.06.2018, Behçet \& Yapar 15383; Aşağı köyOrtaköy arası, orman açıkları, $1680 \mathrm{~m}, 16.06 .2020$, Behçet \& Yapar 18514, Avrupa-Sibirya.

Örneklerin boyu 107 cm'ye (Türkiye florasında 30-70 cm), yaprak uzunluğu 27 cm'ye (Türkiye florasında $3.5-12 \mathrm{~cm}$ ), panikula boyu $16 \mathrm{~cm}$ 'ye varıyor (Türkiye florasinda $6-10.5 \mathrm{~cm}$ )

140. T. thospiticum Chrtek / öz palah

Üçyaka köy yolu $3 . \mathrm{km}$, orman açılları, $1650 \mathrm{~m}$,
23.06.2019, Behçet \& Yapar 16993, end. İran-Turan.

141. Triticum aestivum L. / ekmeklik buğday

Bingöl Üniv. Mühendislik Fakültesi civarı, ekili alan, 1100-1150 m, Behçet 11672, kültür.

142. T. durum Desf. /makarnalık buğday

Bingöl merkez, Kaleönü mah., güneyi, ekili alanlar, 1031 m, 20.05.2020, Behçet \& Yapar 18249, kültür.

143. T. turgidum L. /şişik buğday

Bingöl merkez, Devlet Hastanesi güneyi, bozkır, 1081 m, 20.05.2020, Behçet \& Yapar 1825, kültür.

144. Ventenata dubia (Leers) Coss. \& Durieu / ventenotu

Yelesen köyü batısı, bozkır yamaçlar, 2350m, 28.06.2019, Behçet \& Yapar 17131; Bingöl merkez eski otogar doğusu, yol kenarları, $1112 \mathrm{~m}, 02.06 .2020$, Behçet \& Yapar 18365.

Alt ve üst gluma 5 damarlı (Türkiye florasında alt gluma 5-7 damarl, üst gluma 7-9 damarlı)

145. V. subenervis Boiss. \& Balansa subsp. subenervis/tarla ventenotu

Bingöl merkez, eski otogar doğusu, yol kenarları, 1112 m, 02.06.2020, Behçet \& Yapar 18365, end. Doğu Akdeniz.

146. Vulpia ciliata Dumort subsp. ciliata / kirpikliçim

Topalan köyünün $2 \mathrm{~km}$ güneyi, dere kenarı, 1800-1850 $\mathrm{m}, 20.06 .2017$, Behçet 12195a.

147. ${ }^{*} V$. muralis (Kunth) Nees / pis kirpikliçim

Topalan köyünün $2 \mathrm{~km}$ güneyi, dere kenarı, 1800-1850 m, 20.06.2017, Behçet 12195a, Akdeniz.

148. V. myuros (L.) C.C.Gmel. / arsız kirpikliçim Bingöl merkez, mezarlık batısı, taş ocağı yol ayrımı, orman açıkları, 1200-1300 m, 22.05.2018, Behçet \& Yapar 15011.

149. V. unilateralis (L.) Stace / yumak kirpikliçim Üçyaka köyü, dere kenarı, 1500-1600 m, 10.05.2014, Behçet 9474.

150. *Zingeria biebersteiniana (Claus) P.A.Smirn. subsp. biebersteiniana / oyalısalkım

Topalan-Çirişli köyleri arası 3. km, çayır,1674 m, 29.06.2020, Behçet \& Yapar 18798, İran-Turan.

151. Z Z pisidica (Boiss.) Tutin / burdur oyalısalkım Yelesen köyü yayla yolu, 4. km, dere kenarları, 20150 m, 28.06.2019, Behçet \& Yapar 17015, İran-Turan.

\section{TARTIŞMA ve SONUÇ}

Araştırma alanında Buğdaygiller (Poaceae) familyasindan 59 cinse ait 151 takson (104 tür, 39 alttür ve 8 varyete) tespit edilmiştir. Bu bitkilerden 10'nu endemiktir (\%6.62) (Çizelge 2). Endemik 10 taksondan Pseudophleum anatolicum Doğan, Behçet \& A.Sinan ve Pilgerochloa major (H.Scholz) Doğan \& Behçet sadece Bingöl ilinde yetişen endemik türlerdir. (Doğan ve ark. 2015; Doğan ve Behçet 2019).

Çalışma alanında en fazla taksona sahip ilk 10 cins; Bromus L. (13), Elymus L. (12), Poa L. (9), Phleum L. (6), Hordeum L. (6), Aegilops L. (6), Festuca L. (6), 
Stipa L. (6), Secale L. (5) ve Alopecurus L. (4)'tur (Şekil 13).

Araştırma alanında yayılışı belirlenen buğdaygil üyelerinin en fazla takson içeren ilk 10 cinsinin yakın alanlarda yapılan benzer çalışmalarla (Arabacı ve Yıldız 2004; Karabacak ve Behçet 2014; Yapar ve Behçet 2018;) karşılaştırıldığında Bromus cinsinin bütün çalışmalarda birinci sırada olduğu görülmektedir (Çizelge 3). Ayrıca; Poa, Elymus, Aegilops, Phleum, Hordeum cinsleri siraları değişmekle beraber karşılaştırma yapılan diğer çalışmalarda da ilk 10 cins içerisinde yer almışlardır. Yakın sahalarda yapılan çalışmalarda toplam Poaceae üye sayısı, cinslerin takson sayıları gibi bazı farklı durumlar değişik nedenlere dayandırılabilir. Bu nedenlerden en önemlisi araştırıcının Poaceae üyelerini bir birine benzetmesi nedeniyle sağlıklı toplama yapamayışı, gösterişli çiçekleri olmayan Poaceae üyelerinin gözden kaçmaları, değişen ekoloji ve araştırıcının Poaceae konusunda teşhis ve toplama için yeterli donanıma sahip olmayışı gibi durumlar sayılabilir.

Çizelge 2. Alandan belirlenen endemik taksonlar, tehlike kategorileri ve fitocoğrafik bölge elementleri

Table 2. Endemic taxa determined from the area, risk categories and phytogeographical region elements

\begin{tabular}{|l|l|l|}
\hline $\begin{array}{l}\text { Endemik taksonlar } \\
\text { (Endemic taxa) }\end{array}$ & $\begin{array}{l}\text { Tehlike Kategorisi } \\
\text { (Risk categories) }\end{array}$ & $\begin{array}{l}\text { Fitocoğrafik bölge } \\
\text { (Phytogeographical region) }\end{array}$ \\
\hline 1. Bromus armenus & NT (tehdide yakın) & İran-Turan \\
\hline 2. Elymus erosiglumis & NT (tehdide yakın) & İran-Turan \\
\hline 3. Elymus elongatus subsp. salsus & VU (Hassas) & -- \\
\hline 4. Festuca adanensis & NT (tehdide yakın) & -- \\
\hline 5. Psatysatachys fragilis subsp. secaliformis & -- & İran-Turan \\
\hline 6. Pseudophleum anatolicum & EN (Tehlikede) & -- \\
\hline 7. Secale cereale subsp. ancestrale & VU (Hassas) & -- \\
\hline 8. Trisetum thospiticum & VU (Hassas) & İran-Turan \\
\hline 9. Pilgerochloa major & CR (Kritik tehlikede) & Iran-Turan \\
\hline 10. Ventenata subenervis subsp. subenervis & VU (Hassas) & Akdeniz \\
\hline
\end{tabular}

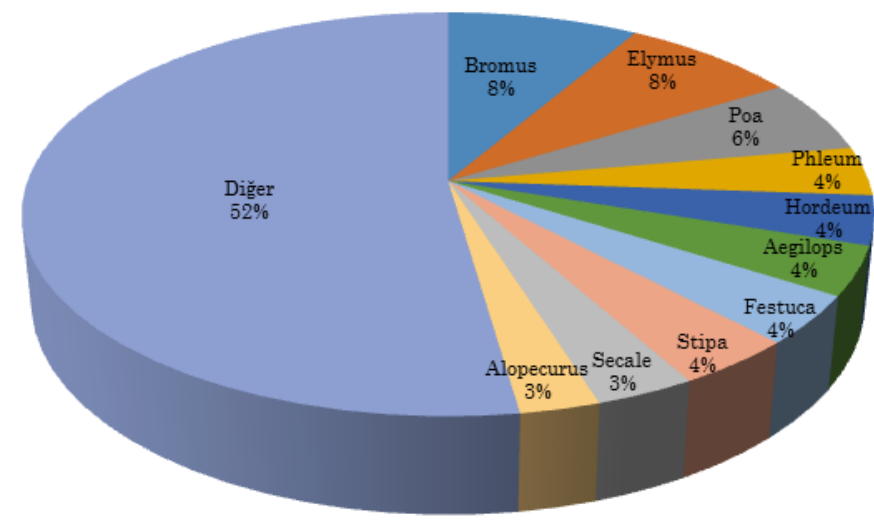

Şekil 13. Çalışmada belirlenen en fazla üyeye sahip ilk 10 cins

Figure 13. Top 10 genera with the most members identified in the study

Taksonların fitocoğrafik bölge element dağılımı şu şekildedir; İran-Turan 29 (\%19.21), Avrupa Sibirya 20 (\%13.24), Akdeniz 9 (\%5.96) ve Çok bölgeli veya fitocoğrafik bölgesi bulunmayan 93 (\%61.59) (Şekil 14). Araştırma alanının İran-Turan fitocoğrafik bölgesinde bulunmasının doğal bir sonucu olarak, alanda İranTuran fitocoğrafik bölge elementi olan takson sayısı diğer fitocoğrafik bölge elementlerinden fazladır.

Tesbit edilen taksonlardan 26 adedi B8 karesi için yeni kayıttır. Bu taksonlardan Bromus hordeaceus subsp. thominii Türkiye'de sadece Zonguldak'tan (A3 karesinden) biliniyordu. Bu taksonun B8 karesinden yayılışının belirlenmesi ile yayılış alanın Türkiye'de de daha geniş olduğu belirlenmiş oldu. Yine alanda yayılışı belirlenen Elymus transhyrcanus şimdiye kadar sadece Erzurum (A8) ve Hakkâri'den (C10) biline bir türdü. $\mathrm{Bu}$ çalışmayla türün Türkiye'deki yayılış alanın daha geniş olduğu ortaya kondu.

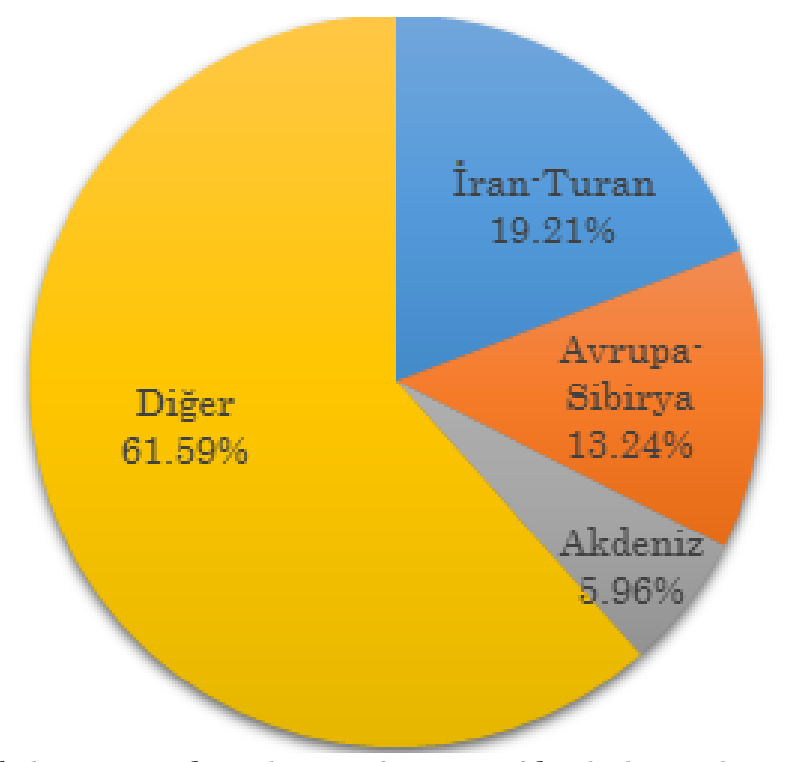

Şekil 14. Taksonların fitocoğrafik bölge element dağılımı

Figure 14. Phytogeographic region elemental distribution of taxa 
Çalışmada tespit edilen 26 taksonda, Türkiye komşu ülke floralarında verilen betimlemelerle uyuşmayan özellikler ortaya konulmuştur. Özellikle Bingöl'den toplanılan Behçet \& Yapar 17645 nolu Alopecurus arundinaceus örneklerinin stolon bulundurması (Şekil 4), çalışma kapsamında incelenen hiç bir florada yer almayan bir karakterdir. Diğer taraftan; Poa trivialis türünün Rusya florasında (Rozhevits ve Shishkin 1963) tespih şekilli rizoma (Şekil 12) sahip örnekleri Poa sylvicola Guss şeklinde farklı bir tür olarak tanımlanmıştır. $\mathrm{Bu}$ güne kadar Türkiye'de $P$. trivialisin tesbih görünümlü rizom yapısına sahip herhangi bir örneğinin toplandiğı bilinmemekte ve Türkiye florasındaki $P$. trivialis tanımında da böyle bir bilgi yer almamaktadır. Ayrica $P$. pratensis örneklerinde hem rizom hem de stolon bulunmaktadır (Şekil 11). Oysaki Türkiye florasında sadece rizomun varlığından bahsedilmektedir. Öte yandan Rusya florasında stolon olabileceği belirtilmektedir. Çalışma kapsamında tespit edilen varyasyonlar (bu çalışmada ilk kez verilen ve özellikle Türkiye florasında yer almayan bazı varyasyonlar), ilgili taksonların betimlemesine katkı sağlayacaktır.

Çizelge 3. Araştırma sonuçlarının yakın çalışmalarla karşılaştırılması

Table 3. Comparison of research results with close studies

\begin{tabular}{|c|c|c|c|c|c|c|c|}
\hline \multirow{2}{*}{\multicolumn{2}{|c|}{$\begin{array}{l}\text { Çapakçur Vadisi } \\
\text { Toplam takson sayısı:151 } \\
\text { (Total number of taxa: 151) }\end{array}$}} & \multirow{2}{*}{\multicolumn{2}{|c|}{$\begin{array}{l}\text { Malatya (Arabacı ve Yildız } \\
\text { 2004) } \\
\text { Toplam takson sayısı:101 } \\
\text { (Total number of taxa: 101) }\end{array}$}} & \multicolumn{2}{|c|}{$\begin{array}{c}\text { Hiro (Yapar ve Behçet } \\
\text { 2018) }\end{array}$} & \multicolumn{2}{|c|}{$\begin{array}{c}\text { Zilan (Karabacak ve } \\
\text { Behçet 2014) }\end{array}$} \\
\hline & & & & $\begin{array}{l}\text { Toplam } \\
\text { sayısı:67 } \\
\text { (Total numb } \\
\text { 67) }\end{array}$ & takson & $\begin{array}{l}\text { Toplam } \\
\text { sayısı:91 } \\
\text { (Total numb } \\
\text { 91) }\end{array}$ & takson \\
\hline $\begin{array}{l}\text { Cins } \\
\text { (Genus) }\end{array}$ & $\begin{array}{l}\text { Takson Sayısı } \\
\text { (number of taxa) }\end{array}$ & $\begin{array}{l}\text { Cins } \\
\text { (Genus) }\end{array}$ & $\begin{array}{l}\text { Takson Sayısı } \\
\text { (number of } \\
\text { taxa) }\end{array}$ & $\begin{array}{l}\text { Cins } \\
\text { (Genus) }\end{array}$ & $\begin{array}{l}\text { Takson } \\
\text { Sayısı } \\
\text { (number } \\
\text { of taxa) }\end{array}$ & $\begin{array}{l}\text { Cins } \\
\text { (Genus) }\end{array}$ & $\begin{array}{l}\text { Takson } \\
\text { Sayısı } \\
\text { (number } \\
\text { of taxa) }\end{array}$ \\
\hline Bromus & 13 & Bromus & 10 & Bromus & 9 & Bromus & 11 \\
\hline Elymus & 12 & Elymus & 6 & Aegilops & 5 & Poa & 8 \\
\hline Poa & 9 & Aegilops & 6 & Poa & 5 & Alopecurus & 6 \\
\hline Phleum & 6 & Hordeum & 5 & Alopecurus & 4 & Elymus & 5 \\
\hline Hordeum & 6 & Alopecurus & 4 & Elymus & 4 & Phleum & 4 \\
\hline Aegilops & 6 & Poa & 4 & Phleum & 4 & Hordeum & 4 \\
\hline Festuca & 6 & Stipa & 4 & Stipa & 2 & Secale & 3 \\
\hline Stipa & 6 & Phleum & 3 & Scale & 2 & Agrostis & 3 \\
\hline Secale & 5 & Lolium & 3 & Hordeum & 2 & Trisetum & 2 \\
\hline Alopecurus & 4 & Melica & 3 & Vulpia & 2 & Koelaria & 2 \\
\hline
\end{tabular}

\section{TEŞEKKÜR}

$\mathrm{Bu}$ çalışma Bingöl Üniversitesi Bölgesel Kalkınma Odaklı Misyon Farklılaşması ve İhtisaslaşması Projesi (Tarım ve Havza Bazlı Kalkınma Alanında) tarafindan (Proje no: PÍKOMBitki.2018.007) desteklenmiştir.

\section{Araştırmacıların Katkı Oranı Beyan Özeti}

Yazarlar makaleye eşit oranda katkı sağlamış olduklarını beyan eder.

\section{Çıkar Çatışması Beyanı}

Makale yazarları aralarında herhangi bir çıkar çatışması olmadığını beyan ederler.

\section{KAYNAKLAR}

Arabacı T, Yıldız B 2004. A Floristical Study on Poaceae spp. Growing Naturally in Malatya Province. Turkish Journal of Botany 28: 361-368.

Behçet L İlçim A 2015. Paracaryum bingoelianum (Boraginaceae), a new species from Turkey. Turkish
Journal of Botany. 39: 334-340.

Behçet L, İlçim A, Yapar Y 2017. Centaurea bingoelensis (Asteraceae), a new species from Turkey. Turkish Journal of Botany 41: 180-188.

Behçet L, Yapar Y, Sinan A 2014. Contribution to the flora of Turkey from B8 square (Bingöl, Elazığ/ Turkey). Biological Diversity and Conversation 7(3): 87-97.

Bor LN 1968. Gramineae (Poaceae). In Towsend, C.C., \& Guest, E. (Eds.). Flora of Iraq. Vol. 9, Ministry of Agriculture Repplic of Iraq, Baghdad, 588 sy.

Bor LN 1970. Gramineae (Poaceae), In Rechinger, H.K. (Ed.) Flora Iranica 70. Akad. Druck- und Verlagsanstalt, Graz, 573 sy.

Cabi E, Doğan M 2012. Poaceae. In A. Güner, S. Aslan, T. Ekim, M. Vural, M.T. Babaç (Eds.). Türkiye Bitkileri Listesi (Damarl Bitkiler). Nezahat Gükyiğit Botanik Bahçesi ve Flora Araştırmaları Derneği Yayını, İstanbul, 690-756.

Cabi E, Doğan M, Karabacak E 2011. Taxonomic revision of the genus Psathyrostachys Nevski (Poaceae: Triticeae) in Turkey. Australian Journal 
of Crop Science 5(12): 1501-1507.

Davis PH, Mill H, Kit T 1985. Gramineae (Poaceae). In Davis P.H. (Ed.) Flora of Turkey and the East Aegean Islands, Vol. 9. Edinburgh University Press, Edinburgh,158-664.

Doğan M, Behçet L 2019. A New Combination and Status Ventenata subenervis subsp. major: Pilgerochloa major (Poaceae, Avenae) From East Anatolia, Turkey. Ot Sistematik Botanik Dergisi 26 (1): 53-65.

Doğan M, Behçet L, Sinan A 2015. Pseudophleum anatolicum, a New Endemic Species of Pseudophleum (Poaceae) from East Anatolia, Turkey. Systematic Botany 40(2): 454-460.

Duran A, Behçet L, Öztürk M 2015. Diplotaenia bingolensis (Apiaceae), new species from east Anatolia, Turkey. Plant Systematics and Evolution 301(1): 467-478.

Ekim T, Koyuncu M, Vural M, Duman H, Aytaç Z, Adıgüzel N 2000. Türkiye bitkileri kırmızı kitabı. Türkiye Tabiatını Koruma Derneği ve Yüzüncü Yıl Üniv., Ankara.

Ersoy Y, Çıngay B, Şekerciler F, Demir O, Cabi E 2019. Checklist of grasses (Poaceae Barn.) in Istanbul. Acta Biologica Turcica 32(3): 149-159.

İlçim A, Behçet, L 2016. Astragalus topalanense
(Fabaceae), a new species from Turkey. Turkish Journal of Botany 39: 74-80.

Karabacak O, Behçet L 2014. The flora of Zilan valley (Erciş-Van/Turkey), Biological Diversity and Conversation 7(3): 20-41.

Rozhevits RY, Shishkin BK 1963. Flora of the U.S.S.R. Vol. II. Published fort he National Science Foundation, Washington, D.C. by the Isreal Program for Scientific Translations, Jerusalem, 622 sy.

Sinan A, Behçet L 2014. Altıkardeş Dağı (Genç-Bingöl) ve çevresinin florası, Biological Diversity and Conversation, 7(3): 98-116.

Tutin TG 1977. Gramineae In Tutin, T.G., Heywood, V.H., Burges, N.A., Moore, D.M., Valentine, D.H., Walters, S.M., Webb, D.B. (Eds) Flora Europaea, Vol. 5, Unv. Press, Cambridge, 118-267.

Yapar Y, Behçet L 2018. Hiro Yaylası (Adakl1Bingöl/Türkiye ) ve çevresinin florası. Biological Diversity and Conversation 11(3): 126-140.

Yıldırımlı Ş 2017. The chorology of the Turkish non tepaloid Monocotyledones species of Cyperaceae Juss., Juncaceae Juss. and Poaceae Barnhart (Gramineae) families. Ot Sistematik Botanik Dergisi 24(2): 173-235. 